\title{
The Structure and Development of the Larval Cuticle of Diataraxia oleracea (Lepidoptera)
}

\author{
By M. J. WAY \\ (From the Insecticides Department, Rothamsted Experimental Station, Harpenden) \\ With three Plates
}

\begin{abstract}
SUMMARY
The main layers comprising the soft cuticle of the Diataraxia larva have been defined and a study made of their formation during development of the 5 th instar larval cuticle.

In soft cuticle the epicuticle is thrown into minute tubercles and consists of three layers-the cuticulin layer, the wax layer, and the cement layer. The cement layer lies outside or partly embedded in the wax layer, but it is either absent or extremely thin over the tips of the tubercles. A polyphenol layer is absent and it is suggested that this layer is present only in hard cuticle.

Beneath the epicuticle is a thin, lightly tanned exocuticle approximately $0.5 \mu$ thick.

The 7-ro $\mu$ thick outer endocuticle is perforated by well-defined pore canals and consists of lamellae containing chitin fibres varying from 100 to $2,000 \mathrm{~A}$ in diameter. Pore canals are absent in the inner endocuticle which when fully developed may be more than $5^{\circ} \mu$ in thickness.

At $25^{\circ} \mathrm{C}$., moulting of the $4^{\text {th }}-5^{\text {th }}$ instar takes less than 48 hours. The cuticulin layer is laid down about 12-24 hours before ecdysis. At about 6-12 hours before ecdysis the exocuticle is formed beneath the cuticulin layer in the outer part of the developing outer endocuticle. Formation of the wax layer begins about $\mathbf{I}$ hour before ecdysis, while the cement layer is secreted only a few minutes prior to ecdysis. The inner endocuticle is laid down during the 5 days after ecdysis.

Prior to ecdysis the pore canals connect the hypodermis to the epicuticle and open into the exuvial cavity at the tips of the epicuticular tubercles. Probably the pore canal lumen is responsible for conduction of the moulting fluid.

Each pore canal contains a well-defined strand of material which occupies but a smail part of the pore canal lumen. The pore canal strands conduct protein and dihydroxyphenol from the hypodermis to form the exocuticle. Exocuticle formation is complete by about $1 \frac{1}{2}$ days after ecdysis. At this stage the pore canal strands become chitinized and sclerotized and the pore canals are cut off from the hvpodermis by the developing inner endocuticle. The pore canals are not responsible for transport of regenerative waxes from the hypodermis after abrasion of the epicuticle.

In areas of hard cuticle there is a relatively thick and heavily tanned exocuticle which continues to develop during the life of the instar. The pore canals maintain contact with the hypodermis throughout the instar and probably remain functional as a conducting system for transport of exocuticular materials.

A study of Verson's glands suggested that the large gland cell secretes a lipoprotein which is discharged on the surface of the epicuticle to form the cement layer. The intercalary cell secretes a phenol which is responsible for the tanning of a plug that blocks the opening of the gland duct after discharge.
\end{abstract}

IOuarterly Journal of Microscopical Science, Vol. 91, part 2, June 1950.] 


\section{INTRODUCTION}

$\mathrm{D}^{\mathrm{ECENT}}$ studies have shown that the insect cuticle is complex in nature. The innermost part, the endocuticle, consists of a delicate association of protein and chitin (Fraenkel and Rudall, 1947), though in many insects tanning of the protein by quinones results in the formation of a hard inalastic exocuticle (Pryor, 1940b) in which the chitin possibly ceases to be of structural significance. Much attention has been paid to the thin superficial epicuticle which has been shown to consist of tanned protein, lipoprotein, and waxes in layers that may be sub-microscopic in size (Wigglesworth, 1947).

However, many biological details still remain to be solved. There appears to be considerable diversity of cuticle structure in different insects and also in different parts of the same insect. Variation in the epicuticle is particularly noticeable: five constituent layers have been demonstrated in Eomenacanthus (Webb, 1947), four in Rhodnius (Wigglesworth, 1947), and two in Sarcophaga (Dennell, 1 346). As regards the pore canals it is generally agreed that they act as a conducting system from the hypodermis to the outermost layers of the cuticle and it has been proved that they are responsible for transport of dihydroxyphenols concerned in the formation of hard cuticle (Wigglesworth, $1947,1948)$. Otherwise there is little or no evidence to support the various suggestions that they take part in the formation of endocuticle and are responsible for transport of enzymes, proteins, and waxes. The relationship of the pore canals to the epicuticle is uncertain, though in the mature cuticle they appear to end beneath it (Richards and Anderson, 1942; Dennell, 1946) and yet in the developing cuticle they open on the surface (Wigglesworth, 1947, 1948). The properties of the pore canals in the mature cuticle are possibly of importance in connexion with problems of permeability (Richards and Anderson, 1942). In some insects they are connected to the hypodermis throughout life (Wigglesworth, 1933; Richards and Anderson, 1942), whilst in others they are present only in the outer endocuticle (Plotnikow, 1904; Dennell, 1946). Their contents may become chitinized (Dennell, 1946) or sclerotized (Wigglesworth, 1948), or may consist merely of a liquid (Richards and Anderson, 1942).

In the present study particular attention has been paid to the epicuticle and pore canals and an attempt has been made to determine the reasons for what appears to be considerable diversity in their structure and properties in different insects. The tomato-moth larva-Diataraxia oleracea L.-was selected for study because many data have been obtained on its resistance to insecticides and it was felt that a knowledge of the cuticle structure was required before problems of permeability could be undertaken. Moreover, Diataraxia, which is a Noctuid species (family Agrotidae), belongs to the economically important group of plant-feeding insects the cuticles of which have not been studied in the light of present knowledge.

A preliminary examination of the Diataraxia cuticle showed a number of interesting features. Although the cuticle is soft there are hardened areas, the 
study of which has provided valuable information on the differences between hard and soft cuticle. The dermal glands are relatively large, and in view of the recent findings of Wigglesworth (1947, 1948), who showed that in Rhodnius and Tenebrio they were responsible for secretion of the cement layer, it was felt that they deserved detailed study in the Diataraxia larva.

\section{MatkRIal and Methods}

Valuable information on the cuticle structure was obtained from the cast exuviae and from strippings of the various layers which were examined in surface view in both the light and electron microscopes. For the latter, special methods of preparation and staining were required. These will be mentioned in the text.

Hand, frozen, and paraffin sections were made, Baker's embedding method being generally used for the frozen preparations and Peterfi's celloidin-paraffin $\left(58^{\circ} \mathrm{C}\right.$. m.p. wax) method for the paraffin preparations. For the preparation of serial sections ester wax (Steedman, 1947) and ceresin wax were less effective than the celloidin-paraffin, though the former was useful for cutting individual sections of $0.5 \mu$ or less for examination in the electron microscope.

Carnoy and Bouin made good general fixatives, but as found by Dennell (1946), Flemming without acetic was unsurpassed for determining details of the pore canals and epicuticle. Baker's formaldehyde was used for lipoid fixation. With regard to stains, preliminary experiments showed that Mallory's triple stain and Heidenhain's iron haematoxylin gave better results than Mann's methyl blue or Delafield's haematoxylin. Use was made of histochemical tests, details of which will be given appropriately in the text.

Except when otherwise stated the observations were made on $5^{\text {th }}$ instar larvae weighing $0.3-0.6 \mathrm{gm}$. (3-5 days old at $25^{\circ} \mathrm{C}$.). The larvae were fed with cabbage foliage and generally had only 5 instars compared with $6-7$ when reared on tomato. At $25^{\circ} \mathrm{C}$. the $5^{\text {th }}$ instar lasts 10 days, of which the first 6 days are spent in feeding and the last 4 days in formation of the cocoon and as a prepupa.

\section{The EPICUTICLe}

Transverse sections of cuticle, $2 \mu$ thick, examined under the light microscope show that the epicuticle is thrown into minute tubercles which are somewhat pointed on the dorsal body-wall but are more dome-shaped ventrally. Electron micrographs of these sections show details of the outlines of the epicuticular tubercles (Pl. I, fig. I). Dorsally these are about $1{ }_{5} \mu$ high and about $\mathbf{I} \mu$ in diameter at the base, though in the mid-ventral line between the prolegs they may be $3 \mu$ high and are readily visible in the light microscope. The tubercles are present in most lepidopterous larvae, and in the earthworm somewhat similar but smaller tubercles (about $600 \AA$ diameter) are present (Reed and Rudall, 1948).

In Diataraxia the tubercles cause the surface area of the epicuticle to be $x \cdot 5-2$ times greater than that of a similar but flat surface, a factor which must decrease efficiency of water conservation. However, this is not a problem for 
most phytophagous insects, though it is significant that in Ephestia where water conservation is important the tubercles are absent or much reduced. The effect of the tubercles on the surface-active properties of the epicuticle must be considerable, a problem of importance in connexion with adhesion of insecticidal sprays and dusts.

\section{Function of the Tubercles}

Tubercles of this type apparently occur exclusively in soft cuticle and it seems probable that they are associated with the mode of life of the softbodied animal. In the first place they would improve flexibility of the epicuticle, and secondly they probably act in much the same way as the stellate

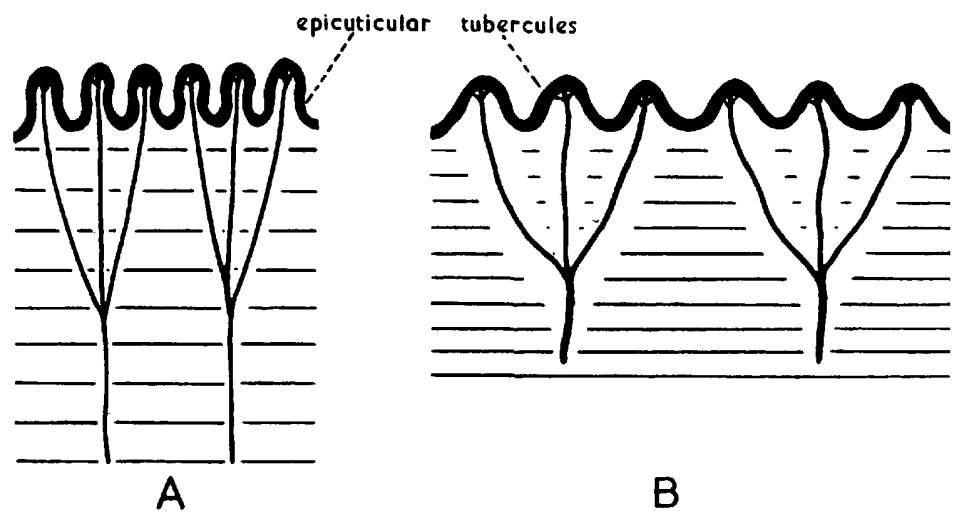

TExT-FIG. I. Schematic transverse sections of epicuticle and outer endocuticle on the ventral surface of the Diataraxia larva showing the effect of cuticle growth. A, new cuticle just prior to ecdysis. $B$, mature cuticle 4-5 days after ecdysis.

folds of the Rhodnius nymphal cuticle (Wigglesworth, 1933) and allow extension and growth of the endocuticle without placing undue strain on the relatively inextensible epicuticle. The effect of growth on the epicuticle may be shown by comparing transverse sections of young and old cuticles. In the newly moulted $5^{\text {th }}$ instar larva the tubercles are pressed together with their bases indented whilst in the mature larva the bases are pulled out (Text-fig. 1 ). Thus the increase in actual surface area with larval growth is relatively small and consequently the formula surface area $=$ weight ${ }^{\mathbf{t}} \times K(=$ constant $)$ which has been used for surface area determinations of approximately cylindrical-shaped insects is liable to considerable error when applied to lepidopterous larvae.

Structure of the Diataraxia epicuticle

Both paraffin and hand sections of unfixed cuticle show an epicuticle which stains grey with sudan black B, whilst the endocuticle remains unstained. 
Perhaps this indicates the presence of lipoid. However, it was of interest to carry out the test described by Wigglesworth (1947) which demonstrated the presence of bound lipoid in the cuticulin layer of the Rhodnius cuticle. Cast exuviae of Diataraxia larvae were boiled with chloroform to remove free lipoid. An exuvium was then gently warmed with chlorinated nitric acid. Initially there was considerable effervescence on the inner surface of the exuvium leaving a thin transparent membrane which on further heating broke down with the liberation of numerous oily droplets. If the heating is stopped just before liberation of the droplets the membrane stains readily in sudan black B. Similar treatment with ro per cent. caustic potash also causes dissolution of the inner layer leaving a thin membrane which fuses and finally breaks down into large numbers of oily droplets.

Thus, in its response to chlorinated nitric acid the exuvium of Diataraxia behaves as does the Rhodnius exuvium. The thin transparent membrane is clearly equivalent to the cuticulin layer of $R$ hodnius which Wigglesworth (1947) suggests is composed of a tanned lipoprotein. Now this membrane which forms the outer surface of the exuvium is insoluble in cold caustic potash and cold concentrated hydrochloric acid. It shows no response to the ninhydrin reagent but stains strongly in sudan black $B$ after gentle warming in acid. In the possession of these properties it resembles the outer epicuticle of the Sarcophaga larva (Dennell, 1946) except that the latter stains in sudan black B without prior acid treatment. It would appear that the cuticulin layer and the outer epicuticle are synonymous.

Prior to ecdysis the endocuticle of soft cuticle is completely digested by the moulting fluid, leaving a very thin exuvium. However, when the exuvium is warmed with chlorinated nitric acid, the initial copious effervescence from the inner surface suggests that this membrane does not consist entirely of the cuticulin layer. Further information was obtained by treating portions of cuticle with concentrated hydrochloric acid and then sectioning and staining with Mallory. In the untreated cuticle the outer region, which ultimately becomes the exuvium, stained bright red, but after treatment in the cold for 2 hours or warming for a few minutes it stained only faintly or not at all. With the light microscope it was not possible to determine any decrease in thickness after acid treatment of the approximately $0.5 \mu$ thick exuvium, but the evidence as a whole suggests that acid treatment removes a layer of basic staining material from the inner surface.

Electron micrographs of the exuvium before and after acid and alkali treatment provide clear evidence of the presence of an inner layer. If a portion of exuvium is examined in the electron microscope the exuvium is sufficiently transparent for some detail to be observed at roo k.v. At 50 k.v. electron scattering is so considerable that little or no detail is visible. Treatment of portions of exuvium with cold 5 per cent. hydrochloric acid, 5 per cent. caustic potash, or diaphanol for 2-3 days, or with i per cent. pepsin overnight causes relativelylittle increase in transparency of the membrane framework to the electron beam. This suggests that the inner layer is not soluble in the above reagents at 
the temperature and during the period of treatment stated. However, treatment of cuticle or exuvium with cold concentrated hydrochloric acid overnight removes the inner layer, leaving the cuticulin layer which is now so thin (probably about $0.1-0.2 \mu$ thick) that it is almost transparent even at $50 \mathrm{k} . \mathrm{v}$.

In its properties the inner layer of the exuvium, although very thin, resembles the exocuticle which hitherto has been said to occur only in hard cuticle. However, it also has properties in common with the inner epicuticle of Sarcophaga (Dennell, 1946). Now a thin exocuticle and an inner epicuticle would occupy a similar position in the cuticle, the only difference being that the former, which is laid down in the outer endocuticle, contains a proportion of chitin in addition to tanned protein, while the latter apparently consists solely of protein or tanned protein. Further data on the nature of this layer will be given later.

Structural detail on the outer surface of the cuticulin layer was determined by a process of shadowing whereby a thin layer of metal cast at an angle to the surface of the preparation was used to throw all irregularities on the surface into highlights and shadows. A portion of newly formed dorsal cuticle was treated with concentrated hydrochloric acid overnight to remove all layers except the cuticulin layer which was then shadowed with nickel and examined in surface view in the electron microscope (Pl. I, fig. 2). Clearly the cuticulin layer is continuous even over the surface of the tubercles, though there are indications of a pore at the tip. Pl. I, fig. 2, shows that removal of the supporting inner layer by the acid has resulted in collapse of the tubercle which has fallen on its side. Otherwise there is no sign that the cuticulin layer has been affected by the acid treatment.

\section{Analysis of the Exuvium of Soft Cuticle}

Apart from excreta and remnants of moulting fluid the Diataraxia exuvium consists solely of those parts of the cuticle which are not digested by the moulting fluid, namely, the exocuticle and the epicuticle. Thus, it provides valuable material for studying the composition on these layers. Prolonged treatment of the exuvium with cold concentrated hydrochloric acid removes all constituents except the cuticulin layer and the wax layer. Similar treatment with 20 per cent. caustic potash leaves the chitin in addition to the cuticulin and wax layers. Such treatments can be used to determine the proportions of the various constituents of the exuvium.

Cast exuviae of $5^{\text {th }}$ instar larvae were divided into batches of about 100. The head capsules were removed because these consist almost entirely of hardened exocuticle. The remaining body cuticle exuviae were ground coarsely and then washed at $60^{\circ} \mathrm{C}$. for about 8 hours with several changes of water. This treatment causes a weight loss of about $15^{-20}$ per cent. which probably represents unabsorbed moulting fluid and excreta.

It should be made clear that the proportions of the various constituents will be expressed as percentages by weight of the exuvium after removal of watersoluble material. Materials soluble in the moulting fluid which are probably 
present in the living epicuticle and exocuticle are not included in the present analysis, in which only the exocuticular chitin, tanned protein, lipoprotein, and wax constituents are considered.

The batches of exuviae were treated as follows:

1. With 20 per cent. caustic potash at $25^{\circ} \mathrm{C}$. Treatment was carried out in platinum crucibles and filtration and washing in Gooch filters.

2. With concentrated hydrochloric acid at $25^{\circ} \mathrm{C}$. Treatment throughout was carried out in Gooch filters.

3 and 4 . As I and 2, except previously extracted with chloroform at $60^{\circ} \mathrm{C}$., the weight of the chloroform extracts (i.e. the wax layer) being determined.

Twenty-four hours after treatment, and at 2-day intervals afterwards, the residue was washed thoroughly with water, dried at $60^{\circ} \mathrm{C}$. over phosphorus pentoxide, and weighed until constancy was reached. This occurred in all treatments after $5-7$ days.

The percentage weights of residue remaining after treatment are given in Table I.

TABLE I. Weights of Residue remaining after Treatment of Last Instar Exuviae with 20 per cent. Caustic Potash and Concentrated Hydrochloric Acid

\section{Treatment}

20 per cent. caustic potash Chloroform extracted +20 per cent. caustic potas Concentrated $\mathrm{HCl}$.

Chloroform extracted + concentrated $\mathrm{HCl}$ :
Wts. of residues

as per cent. of exurium

$31 \cdot 9$

$25 \cdot 4$

19.5

13.3

The wax extracted by the chloroform amounts to $4 \cdot 7-5 \cdot 2$ per cent. of the exuvium, a figure which agrees closely with the $4-4.5$ per cent. obtained by Bergmann (1938) for silkworm exuviae, particularly when it is remembered that the latter determination was made on exuviae which had not been extracted with water and thus contained a higher proportion of non-lipoid material. Table I shows that in both acid and alkali treatments the reduction in weight of residue after chloroform extraction of exuviae is just over 6 per cent. This reduction may be accounted for by the absence of the wax layer, which at $25^{\circ} \mathrm{C}$. is not dissociated by either acid or alkali.

The residue after acid treatment consists of the cuticulin layer, while that remaining after alkali treatment contains chitin in addition. The difference in weight gives the proportion of chitin which therefore represents about 12 per cent. of the exuvium. Thus, proportions of exuvium constituents are: wax 5 per cent., cuticulin 13 per cent., chitin 12 per cent., other constituents (mainly protein) 70 per cent.

The chitin content corresponds with the 10-20 per cent. present in the silkworm exuvium (Kuwana, 1933; Bergmann, 1938). To confirm the chitin figure, chloroform-extracted exuviae were treated with 20 per cent. caustic 
potash at $60^{\circ} \mathrm{C}$. for 2 days. The residue which had not reached constant weight was $19^{-2}$ per cent. of the original. It was then immersed in cold concentrated hydrochloric acid for $\mathrm{I}$ day to hydrolyse the chitin and a residue of 6.8 per cent. was left. The difference of 12.4 per cent. confirmed the figure for chitin obtained above, but the low figure for the residue of cuticulin shows that this material is dissociated by caustic alkali at $60^{\circ} \mathrm{C}$. However, destruction is slow because remnants still remain even after treatment for $\mathrm{I}$ week. The cuticulin layer is also slowly dissociated by concentrated hydrochloric acid at $60^{\circ} \mathrm{C}$.

\section{Nitrogen Content of Exuvium}

To obtain some data on protein content, nitrogen determinations of the exuvium and of the exuvial residues after acid treatment were made by the micro-Kjeldahl technique. Table II shows the figures obtained for percentages of nitrogen.

TABLE II. Nitrogen Contents of Exuvium and of Residues after Acid Treatment

Treatment

Per cent. nitrogen

Exuvium after washing with water

I I*2

4.I

Conc. $\mathrm{HCl}$ at $25^{\circ} \mathrm{C}$.

Chloroform at $60^{\circ} \mathrm{C}$. + conc. $\mathrm{HCl}$ at $25^{\circ} \mathrm{C}$.

$5 \cdot 9$

The residue after hydrochloric acid treatment consists of cuticulin layer plus wax layer. If the latter is discounted on the basis that it contains no nitrogen, the calculated nitrogen figure for the cuticulin layer is 5.7 per cent which agrees with the 5.9 per cent. content of the residue after chloroform plus hydrochloric acid treatment.

Since there is no evidence to suggest that the nitrogen represents anything but protein and chitin, approximate figures for percentages of protein in the cuticulin layer and in the inner layer of the exuvium may be obtained by multiplying the nitrogen figure by $6 \cdot 25$ after allowance has been made for the nitrogen present as chitin (theoretical figure $=6.9$ per cent.) and the $\circ$ per cent. nitrogen in the wax layer.

The calculated percentages of the exuvium constituents with nitrogen and protein contents are given in Table III.

Table III. Percentages and Protein Contents of Exuvium Constituents

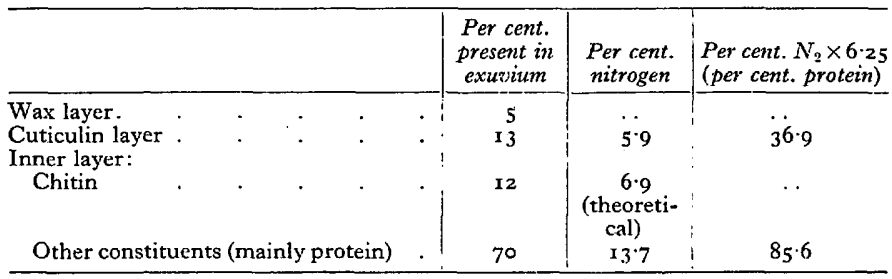


As will be shown later the figure of 70 per cent. for other constituents includes the cement layer which, however, must be present in very small proportion. Because of this it is probable that the correct figure for the proportion of nonchitinous constituents of the inner layer is slightly lower than that shown.

The evidence in Table III suggests that the inner layer of the exuvium contains chitin and thus is an exocuticle and not an inner epicuticle. From the table it can be calculated that the exocuticle contains about 15 per cent. chitin and about 73 per cent. protein. Tanning materials and pigments would be included in the remaining 12 per cent.

As previously mentioned the above figures are not strictly accurate, but they demonstrate that the cuticulin layer contains protein in addition to lipoid and that the inner layer is a thin exocuticle. If it is assumed that the cuticulin layer consists solely of lipoprotein, the lipoid content is in the region of 60 per cent. This would account for the copious evolution of oily droplets which occurs when the cuticulin layer is dissociated with hot caustic potash or chlorinated nitric acid.

\section{The Wax Layer}

For a number of insect species Wigglesworth (1945) and Beament (1945) have shown that a thin layer of orientated wax on the surface of the epicuticle is responsible for waterproofing. Abrasion or treatment with a wax solvent disorganizes the wax layer and increases permeability of the cuticle. Table IV shows the results of such treatments with batches of mature last instar larvae of Diataraxia as test-subjects. All larvae were killed in ammonia and the spiracles, head, and anus blocked with celloidin before determination of transpiration was carried out.

TABLE IV. Water Loss of the Cuticle in Dry Air at $25^{\circ}$ C. after Abrasions and Chloroform Treatment

Treatment

Small area of dorsal surface gently abraded with alumina Larvae immersed in cold chloroform $\frac{1}{2}$ minute Larvae suspended over chloroform hour .

Larvae untreated

$\begin{gathered}\text { Water loss } \\ \text { mg./larva/hour } \\ 10.2 \\ 12.6 \\ 10.8 \\ 3.5 \\ 2.8\end{gathered}$

Wigglesworth has shown that removal of the wax layer exposes material which stains readily when the insect is immersed in ammoniacal silver hydroxide. In the mature Diataraxia larva such staining is never intense but consists of a light-red colour in the framework of the epicuticle. It is interesting that gentle abrasion often does not expose silver staining areas, though the increased permeability which results may be almost as great as that caused by harsh abrasion (see Table IV). Clearly the properties of waterproofing reside in the superficial layers and not in the framework of the epicuticle.

Observations of Ramsay (1935), Wigglesworth (1945), and Beament (1945) show that at a particular temperature-the critical temperature-the wax 
layer undergoes a change of phase and allows water to pass readily through the cuticle. Text-fig. 2 shows graphically the weight losses of last-instar Diataraxia larvae in mg. per larva per hour in dry air at various temperatures. Two sets of

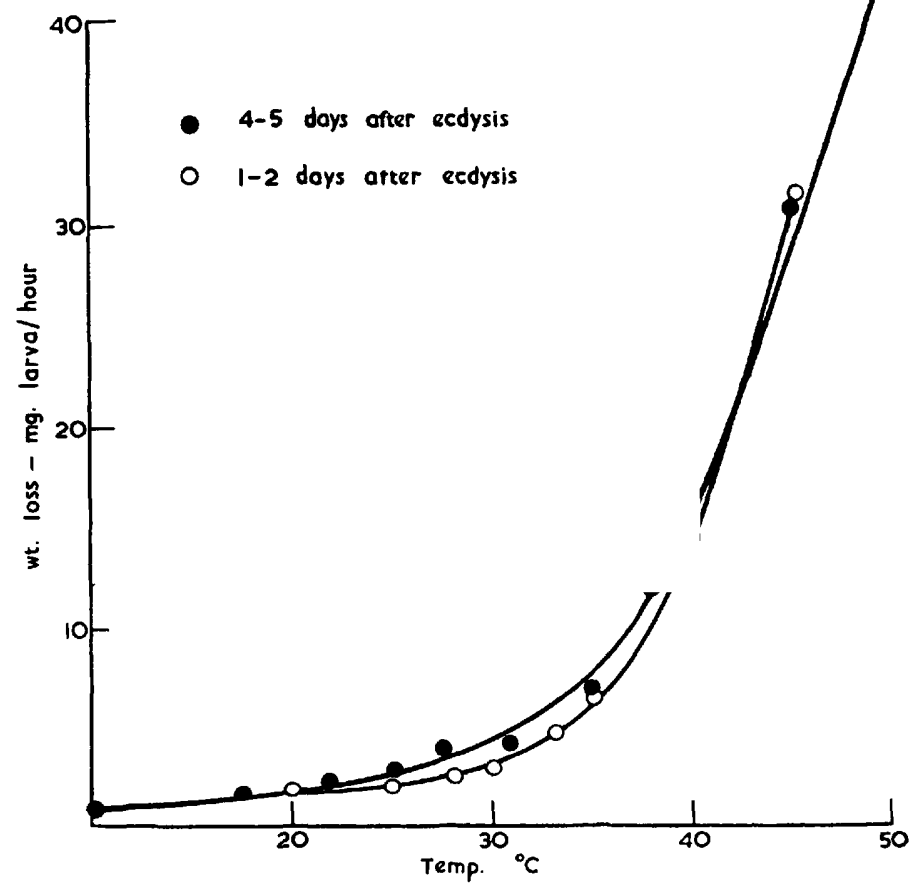

Texr-FIG. z. Graph showing relationship of water loss to temperature for the last instar larva of Diataraxia.

data are shown, one with I- to 2-day-old larvae and the other with 4- to 5-dayold larvae. Both show that the critical temperature lies in the region of $31-$ $34^{\circ} \mathrm{C}$. For comparison the critical temperature obtained by Wigglesworth (1945) for other larvae living in a similar habitat are: Nematus, c. $35^{\circ} \mathrm{C}$.; Pieris, $c .42^{\circ} \mathrm{C}$. Thus the waterproofing mechanism in the Diataraxia larval cuticle is essentially similar to that of the range of insect species examined by Wigglesworth (1945) and Beament (1945).

Data already described show that the chloroform-soluble material of the 
Diataraxia larva exuvium, which is considered to form the wax layer, constitutes about 5 per cent. by weight of the exuvium or about 0.47 per cent. of the dry weight of the complete 5-day-old cuticle.

\section{The Cement Layer}

Paraffin sections of soft cuticle sometimes show a thin layer of material which has separated or partly separated from the outer surface of the epicuticle. It has the appearance of a network somewhat like a minute sheet of chicken wire which when in position lies in the depressions surrounding the epicuticular tubercles. The tubercles themselves project through the holes in the network. The layer can be demonstrated in sections of abraded cuticle, when it is seen that abrasion has torn away short lengths of the layer which remains attached here and there to the body of the epicuticle. The layer is remarkably thin and difficult to see, particularly since it does not stain with acid dyes, and with basic dyes stains only very weakly in comparison with the epicuticle. In paraffin sections it stains a dark grey with sudan black B, though it is perhaps most readily demonstrated by its reddish colour after chloroform treatment or abrasion followed by immersion in ammoniacal silver oxide (P1. II, fig. 15).

The ease with which this layer can be separated from the epicuticle by abrasion and chloroform treatment suggests that it is not strongly bound. It occupies the position of the cement layer as described by Wigglesworth (1947, 1948) for Rhodnius and Tenebrio since it lies on the outside of the cuticle and is separated from the cuticulin layer by a layer of chloroform soluble material-presumably the wax layer.

A sheet of larval cuticle freed from all underlying cellular material was fixed in Carnoy and stuck firmly to a glass slide, endocuticle downwards. The preparation was dried on a hot plate and then a thin layer of collodion poured over the surface of the epicuticle and allowed to dry. Successive layers were poured on and dried until a tough membrane was obtained which was then peeled away, carrying with it the cement layer. It was laid on a fresh slide, allowed to dry, and the celloidin was then dissolved away in acetone. The remaining cement layer was deeply stained with sudan black B or iron haematoxylin and examined in the light microscope (PI. I, fig. 3).

As far as can be determined the cement layer covers the whole body. Its presence was demonstrated on the hard cuticle of the head and muscle insertions over the flat surface of which it forms a thin continuous covering (Pl. I, figs. 3 and 5). Variations in intensity of staining suggest differences in thickness which give the impression that the layer has been formed by flowing as a liquid over the surface of the epicuticle and setting somewhat unevenly.

Further details were obtained by examination in the electron microscope. It was found that collodion-stripped preparations were generally contaminated with impurities in the collodion (Pl. I, fig. 5), and the best material was obtained by warming portions of the cuticle in chloroform. Pieces of cement layer sufficiently large for examination in the electron microscope could then 
be scraped off with a fine needle. These were mounted on microscope grids without supporting collodion film and examined in surface view (Pl. I, fig. 4). The layer is probably not more than $0.1 \mu$ thick as observed in the electron microscope. In limited areas, generally on the ventral body-wall and in the neighbourhood of the muscle insertions (P1. I, fig. 5), it sometimes covers the tubercles, but elsewhere the tips of the tubercles project through it, though if the layer here is extremely thin it might be torn away during the stripping process. Nevertheless it is difficult to assign a protective function to this layer since it affords either little or no protection to those areas of the cuticle which are most likely to become abraded. Apparently the cement layer is partly embedded in the wax layer. Thus although it does not provide protection, it may act as a supporting framework to the wax layer.

In electron micrographs of intact exuvium the cement layer is seldom visible, probably because it causes insufficient electron scattering to contrast against the diffused scattering of the approximately $0.5 \mu$ thick exocuticle. Examination of the epicuticle after overnight treatment with cold concentrated hydrochloric acid or 20 per cent. caustic potash shows no sign of it. This suggests that the cement layer is dissolved by concentrated acids and alkalis, an observation which was confirmed by experiments in which drops of concentrated acid and alkali were placed for $x$ hour on portions of fresh cuticle, which were then fixed in Carnoy and subjected to the collodion stripping process. Strippings from the treated areas did not contain a cement layer. However, in preparations where only the undersurface of a portion of exuvium was treated for 2-3 hours with concentrated hydrochloric acid the greater part of the exocuticle was removed, leaving the cement layer intact and clearly visible in electron micrographs (Pl. I, fig. 6).

The cement layer cannot be removed from the cuticle without prior treatment with a wax solvent, and thus it was not possible to carry out histochemical tests on fresh material. Portions of cement layer removed from Carnoy-fixed cuticle were soluble in warm concentrated hydrochloric acid and fused into a yellowish mass and finally dissolved when warmed with 20 per cent. caustic potash. A few oily droplets were observed when the cement layer dissolved in potash. The response to ninhydrin was negative, though even after Carnoy treatment the cement layer stained grey with sudan black B. Doubtful significance is attached to the above observations, though they suggest that the cement layer of Diataraxia has properties somewhat similar to the cement layer of Rhodnius and Tenebrio (Wigglesworth, 1947, 1948).

\section{Pore Canals in the Epicuticle}

Sections of the Diataraxia cuticle show that a single pore canal runs inside each epicuticular tubercle. Otherwise no further detail can be determined under the light microscope because structures within the tubercles are too small for resolution. Portions of soft exuvium examined in surface view in the electron microscope show no indications of pore canal openings, but if the exuvium is treated with any of the following: (1) diaphanol for 3 days; (2) 
5 per cent. caustic potash or 5 per cent. hydrochloric acid overnight; (3) I per cent. pepsin at $\mathrm{pH} 2$ and $32^{\circ} \mathrm{C}$., an aperture is disclosed at the tip of each epicuticular tubercle (Pl. I, fig. 7). This undoubtedly is the external opening of the pore canal. The apertures are also disclosed after treatment with concentrated mineral acids and concentrated alkalis which also remove the exocuticle. Clearly the pore canals pass through both exocuticle and epicuticle, but in the mature epicuticle they appear to be blocked by a plug of material which is fairly easily dissolved or dislodged. Evidence for the presence of the plug is given in preparations of the cement layer by the collodion stripping process which removes a lump of material from the tip of each tubercle (Pl. I, fig. 5). Moreover, the small irregular swellings at the tips of the tubercles, as shown in electron micrographs of the dorsal cuticle (Pl. I, fig. I), suggest a cap of secreted material. Perhaps the plugging of the pore canals is responsible for their not being observed in the mature larval epicuticle of Sarcophaga (Dennell, 1946) and the adult epicuticle of Periplaneta (Richards and Anderson, I942).

Data on the penetration of water-soluble stains such as ammoniacal silver hydroxide which will be given later suggest that during the pre-ecdysial period the pore canals are open and provide a channel for rapid penetration of water-soluble material to the hypodermis. Thus untreated preparations of the newly formed epicuticle should show open pore canals. However, all the preparations made were contaminated with either remnants of hypodermis or newly formed endocuticle and were opaque to the electron beam. The absence of the irregular cap at the tip of the tubercles, and failure to remove it by the stripping technique, support the evidence that the pore canals are open in the newly formed cuticle.

The readiness with which the plug can be removed from the pore canal openings in the mature epicuticle suggests that the pore canals may still provide a relatively easy path for the penetration of water soluble materials, in particular through the lipoprotein cuticulin layer.

\section{Pore Canal Contents and the Epicuticle}

Transverse sections of mature cuticle stained in Mallory or iron haematoxylin show that the pore canal contents form well-defined tree-like structures in the outer endocuticle (Pl. I, fig. 8). A single branch runs inside each epicuticular tubercle and appears to make contact with the exocuticle or epicuticle near the tip. Further detail is given by electron micrographs. A portion of ventral cuticle was laid endocuticle downwards on concentrated hydrochloric acid for to minutes. The endocuticle was disorganized, leaving the exocuticle intact, and under the high power of the light microscope the pore canal strands were observed as a mass of hair-like processes projecting from the under surface of the exocuticle. After fixation in Carnoy, remnants of the endocuticle were gently brushed away and the remaining membrane examined in surface view in the electron microscope. Pore canal strands were seen passing up and branching over the inner surface of each tubercle (Pl. I, fig. 9). Internally the 
strands from adjacent tubercles, 6-12 dorsally and 4-7 ventrally, converge and unite to form a single main strand, the whole forming the tree-like structure observed in the light microscope (PI. I, fig. 8).

The pore canal strands are not digested by the moulting fluid, and thus remnants usually remain attached to the cast exuvium. Pl. I, fig. ro, is an electron micrograph of a portion of exuvium treated with osmium tetroxide which has acted as an electron stain. This preparation shows clearly that within the tubercle each pore canal strand divides into a number of fine filaments which enter the epicuticle or exocuticle. The ramifications of these filaments within and between the epicuticular tubercles are best seen in more heavily stained preparations and show that each pore canal strand is intimately associated with the outer layers of the cuticle. If the exocuticle is removed by treatment with concentrated hydrochloric acid overnight and the remaining cuticulin layer treated with Altmann and examined in the electron microscope the fine osmium-staining filaments have disappeared. This may suggest that the filaments lie within the exocuticle, but in view of the possible effects of the acid treatment the evidence is unreliable.

\section{Composition of Pore Canal Contents}

Strands of material in the pore canals have been observed by a number of authors and were described as consisting of cytoplasmic or cuticular material mainly on the basis of their staining properties. A more detailed study of the pore canal contents of the mature Sarcophaga larva (Dennell, 1946) showed that these contained chitin, though in the immature stage they are apparently cytoplasmic. Campbell's (1929) modification of the van Wisselingh test for chitin as described by Dennell (1946) was carried out on the mature larval cuticle of Diataraxia. The pore canal strands gave a strong positive response. However, unlike the acidic staining pore canal contents of Sarcophaga, the pore canal strands of Diataraxia stain strongly with basic dyes. Moreover, the strands are not digested at moulting nor are they destroyed by $\frac{1}{2}$ hour treatment of the fresh cuticle with cold concentrated hydrochloric acid. Treatment of a portion of cuticle with cold concentrated nitric acid for $\frac{1}{2}$ hour followed by fixation with Carnoy, sectioning, staining, and examination under the light microscope shows that the strands have fused into a number of particles which still stain red with Mallory. However, the pore canal strands are completely destroyed by treatment overnight with cold concentrated acid.

In the possession of the above properties the pore canal strands are identical with the exocuticle. Since they are attached to the exocuticle they may be considered as part of this layer, the probable function of which is to support the delicate cuticulin layer and also to act as a bridge between the lipophil cuticulin layer and the lipophobe endocuticle. In the latter respect the pore canal strands must be important because they form exocuticular roots running into the endocuticle. 


\section{The ENDOCuTICLE}

The soft endocuticle of the Diataraxia larva is divisible into an outer endocuticle which over most of the body is $7-10 \mu$ thick, and an inner endocuticle which may be $50 \mu$ or more in thickness. The former shows a somewhat stronger staining response to acidic dyes, though after Flemming fixation it stains readily in iron haematoxylin in contrast with the inner endocuticle. The outer endocuticle also possesses well-defined pore canals containing basic staining pore canal strands (PI. I, fig. 8) and it is clearly lamellate, whereas the more widely spaced lamellae of the inner endocuticle are less easily defined.

\section{The Outer Endocuticle}

After fixation in Flemming, $2 \mu$ thick sections of the outer endocuticle were cut parallel to the cuticle surface, stained in iron haematoxylin, and examined in the light microscope. In such preparations the lamellae are seen to be fibrous in nature, though no detail can be determined. On the ventral integument between the prolegs the pore canals are much larger than elsewhere and are well-defined holes sometimes $3 \mu$ in diameter in the periphery of the outer endocuticle and becoming somewhat smaller in the deeper lamellae until they disappear completely in the region of the inner endocuticle. In each canal one or more heavily stained dots-the pore canal strands-are visible and it is clear that these occupy but a small part of the pore canal lumen (PI. I, fig. II). The difference between outer and inner endocuticle is in part due to the chitin constituents, for if the cuticle is treated overnight with 5 per cent. caustic potash at $100^{\circ} \mathrm{C}$. to remove protein and is then sectioned, the inner and outer endocuticles still show differences in their ability to absorb stains. The latter is more retentive of both acidic and basic dyes, and transverse and surface sections stained with iron haematoxylin show fibrous structure and pore canals in which the chitinized pore canal strands are still visible.

The lamellation of the endocuticle is well defined after alkali treatment. This observation contrasts with that of Richards and Anderson (1942) who state that in the Periplaneta endocuticle the lamellations disappear after potash treatment, though Yonge (1932) and Dennell (1946) observed that lamellation remained after such treatment of the fore-gut cuticle of Homarus and the body cuticle of the Sarcophaga larva. Treatment of a portion of Diataraxia cuticle with concentrated hydrochloric acid for about 5 minutes followed by fixation and sectioning shows that the lamellations have disappeared. These observations suggest that the chitin is concentrated in sheets and that it is responsible for the lamellations observed.

Fine detail was determined by studying strips peeled from the outer endocuticle which were then examined in surface view in the light and electron microscopes. Prior to being mounted on the electron microscope grid the strips were kept in water for about $\frac{1}{2}$ hour and consequently water-soluble protein was largely removed. The strips were generally too thick, but in places, and in particular at the edges of the preparations, areas one lamella thick were $242 I \cdot 14$ 
obtained which were suitable for examination by transmission in the electron microscope. Relatively large sheets of outer endocuticle consisting of single lamellae were readily obtained by dissection from the old cuticle of larvae just prior to mouiting. At this stage the old endocuticle is in process of being digested, the initial stages of which result in a softening or destruction of the bonds between individual lamellae. In such preparations it is probable that water-soluble proteins had been removed and possibly some digestion of other constituents had occurred. However, under the electron microscope these preparations showed no difference in structure from the strippings of the mature cuticle and they were therefore used in most of the treatments described below.

Electron micrographs of lamellae from the outer endocuticle show that the pore canals are subdivided (PI. I, fig. 12). Probably each subdivision contains a single branch of tree-like pore canal strand. Prior to examination the preparation shown in Pl. I, fig. I2, was treated with pepsin to remove protein and thus the micrograph shows only the chitin constituents. However, examined by transmission this lamella and also lamellae treated with diaphanol and caustic potash showed no detectable difference from untreated lamellae. In all preparations little structural detail was observed in the framework of the lamella, though there are indications of the presence of fibres or fibre bundles. These fibres must consist of chitin, though Pl. I, fig. 12, shows that considerable areas of chitin are apparently structureless. However, the impression given by such pictures is incorrect, for if a lamella is metal-shadowed and then examined in the electron microscope, a system of fibres far more complex than is apparent in transmission pictures is visible on the surface of the lamella (P1. II, fig. 13). Clearly the apparently structureless areas consist of a mass of small chitin fibres orientated at random in the plane of the lamella. The smallest fibres are rather less than $100 \AA$ in diameter, while the largest fibre bundles may be $2,000 \AA$ in diameter. The fibres are readily visible in shadowed preparations of untreated lamellae, but prior treatment with pepsin, diaphanol, or caustic potash causes some improvement in definition. Possibly the better definition is due to removal of water-insoluble protein constituents, but the micrographs were not sufficiently clear to determine any significant difference in the appearance of the fibres.

Richards and Korda (1948) obtained transmission micrographs of a number of insect membranes, including the chitin of the tracheal membrane of Periplaneta which consists of fibrils and fibres $100-300 \AA$ in diameter and similar in appearance to those of the outer endocuticle of Diataraxia. However, 'unexpected diversity in chitin patterns' was found in other insect membranes, some of which appeared homogeneous. The present work has shown that such transmission micrographs may give a false impression of the structure of chitinous membranes. Rather thick preparations may appear homogeneous until shadowed, when chitin fibrils are clearly revealed. Even thin preparations examined by simple transmission give little indication of the chitin pattern, and it seems possible that the diversity in structure of insect membranes 
examined by Richards and Korda (1948) is more an index of their different thicknesses than a variation in chitin cross-linkages.

To summarize: present evidence suggests that the outer endocuticle is made up of about 1o lamellae approximately I $\mu$ apart. The lamellae are pierced by well-defined pore canals which may be $\mathrm{I}-3 \mu$ in diameter in peripheral lamellae but decrease in diameter as the pore canal strands which they surround, converge and combine in the deeper lamellae of the outer endocuticle. Each lamella comprises a sheet of randomly orientated chitin fibres and bundles of fibres presumably associated with water-insoluble and water-soluble proteins. The chitin is responsible for the lamellations whilst protein is the main constituent of the interlamellar region.

Fraenkel and Rudall (1947) described X-ray and swelling data on cuticles of Sarcophaga which suggest layers of chitin separated by protein. The present findings are in agreement with this general statement. However, Fraenkel and Rudall suggest that the association implies a model of alternating mono-layers of chitin and protein. This theory is based on the fact that three amino-acid residues occupy almost the same volume as one chitobiose residue and for equal lengths of chitin and protein chains the weight ratio is $55: 45$, which is a close approximation to the $54: 46$ ratio obtained in their determination with the Sarcophaga larval cuticle. Table V shows that the $55: 45$ ratio does not occur in other soft-bodied insects so far studied, and present work on development of the Diataraxia cuticle shows that the chitin-protein ratio does not approach $55: 45$ at any stage in cuticle growth. Moreover, the Diataraxia outer endocuticle consists of approximately $0.5 \mu$ thick lamellae containing mainly chitin separated by layers consisting mainly of protein, and it is difficult to conceive how this structure can be explained in terms of an alternating monolayer theory.

\section{TABLE V. Ratios of Chitin and 'Protein' present in the Last Instar Larval Cuticle of Various Lepidoptera}

$\begin{array}{lcccc} & & & \text { Chitin } & \text { 'Protein'* } \\ \text { Ephestia elutella. } & . & . & 18 & 82 \\ \text { Plutella maculipennis } & . & . & 20 & 80 \\ \text { Pieris brassicae.. } & . & . & 35 & 65 \\ \text { Diataraxia oleracea } & . & . & 36 & 64 \\ \text { Plusia gamma . } & . & . & 38 & 62 \\ \text { * Material soluble in } 5 \text { per cent. } \mathrm{KOH} \text { at } 90^{\circ} \mathrm{C} \text {. }\end{array}$

Electron micrographs of cellulose from the primary wall of various plant fibres (Mühlethaler, 1949) are remarkably similar to those of the outer endocuticle of Diataraxia. In the wall of a plant cell the cellulose chains form visible lamellae (Preston and Astbury, 1937) and-at any rate in the developing primary wall-are associated with protein (Tupper-Carey and Priestley, 1924). The similarity of structure is understandable since both primary cell wall and outer endocuticle require similar specialized properties, notably tensile strength 
ombined with the ability to undergo considerable stretching, during meristematic activity in the former, and just after ecdysis in the latter.

\section{The Inner Endocuticle}

The inner endocuticle is that part of the cuticle which is laid down after moulting. The lamellae are larger and more widely spaced than in the outer endocuticle, a condition similar to that in the soft-bodied Sarcophaga larva (Dennell, 1946). In Diataraxia this difference is certainly in part due to the effect of growth, because most of the inner endocuticle is laid down after the first day and, unlike the outer endocuticle, is subjected to relatively little stretching and consequent 'thinning' of the lamellae.

In transverse sections under the light microscope the lamellae are not readily distinguished from the interlamellar tissue. However, they separate individually during digestion of the endocuticle at moulting and their fibrous structure is readily visible in the latter stages of this process. Pore canals and pore canal strands are absent in the inner endocuticle, a condition which appears to be typical of soft-bodied larvae (Plotnikow, 1904; Dennell, 1946).

Electron microscope studies have as yet produced little additional information on the structure of the lamellae. Strips of cuticle examined in surface view are rather opaque to the electron beam, partly because the lamellae are thicker and also because they seem to be less readily separated than lamellae of the outer endocuticle. Strippings and transverse sections of the inner epicuticle showed only that large fibre bundles are present and these are larger than those in the outer endocuticle.

\section{Formation of the 5TH Instar Diataraxia Cuticle}

Moulting of the Diataraxia larva is a relatively rapid process-the time between cessation of feeding of the $4^{\text {th }}$ instar and emergence of the $5^{\text {th }}$ being rather less than 2 days at $25^{\circ} \mathrm{C}$. The time scale for the stages in development cannot be determined exactly owing to rapidity of the various processes which occur mainly in the $\mathrm{I} 2$ hours prior to moulting. These processes do not occur simultaneously throughout the body but are initiated in the head region and show an axial gradient (cf. Kühn and Piepho, I938).

In the cuticle the first visible sign of moulting is about 6-12 hours after cessation of feeding when cell division begins in the hypodermis in an apparently haphazard manner (Text-fig. $3 a$ ), the cells having no definite shape and the cell walls being difficult to define. At about 24 hours, formation of the epicuticle begins in the head region and then progresses posteriorly. Paraffin sections of the body region show that most of the hypodermal cells have become elongated ( $20 \mu$ or more in length) as viewed in transverse section. In surface view they are approximately rectangular with measurements varying from $4-7 \mu$ by $7-12 \mu$.

The newly formed epicuticle forms a very fine continuous membrane over the hypodermis and at this stage is not clearly separate from the overlying $4^{\text {th }}$ instar cuticle. Well-defined epicuticular tubercles appear as needle-like 
points on the dorsal integument and as indented cones ventrally. About $30-50$ overlie each hypodermal cell, though there is much variation according to position, the tubercles being larger and less numerous ventrally than dorsally.

At about 12 hours prior to ecdysis the new epicuticle, except at the muscle insertions, becomes separated from the overlying $4^{\text {th }}$ instar cuticle and
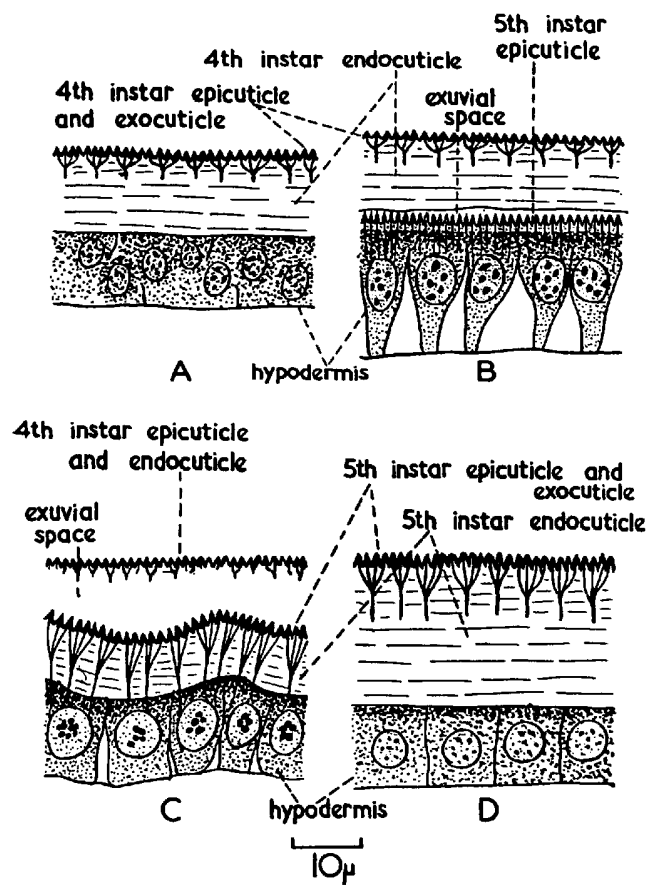

Text-FIg. 3. The formation of the 5 th instar lava cuticle of Diataraxia. Transverse sections of developing cuticle: A, about 36 hours before ecdysis. B, about 12 hours before ecdysis. C, immediately before ecdysis. $D$, about 2 days after ecdysis.

moulting fluid begins to digest the latter. At the same time formation of the new endocuticle begins and pore canals and pore canal contents become visible (Text-fig. $3^{b}$ ). The latter are in the form of filaments each of which originates in the neighbourhood of the nucleus of a hypodermal cell and passes out through a pore canal in the endocuticle to an epicuticular tubercle. In Golgi preparations of the developing cuticle the pore canal contents are visible within the hypodermal cells either as solid staining filaments or as rows of minute dots. 
When about $3-4 \mu$ of endocuticle has been laid down, the epicuticle and pore canal filaments begin to show strong basic staining properties. Groups of 5-12 pore canal filaments converge in the endocuticle to form a single main strand which enters the hypodermal cell. Thus each group forms a tree-like structure-a system characteristic of lepidopterous larvae (Plotnikow, I904; Kuwana, 1933; Kühn and Piepho, 1938).

Sections of the soft cuticle of the moulting 4 th instar larva just prior to ecdysis show that the old cuticle has been completely digested and that an approxi-

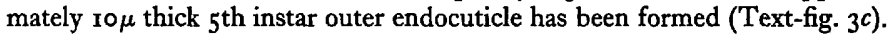

For some hours after ecdysis the caterpillar remains quiescent. During this period pigments are laid down in the hypodermal cells and epicuticle, and other processes take place which will be discussed later.

The pore canal filaments remain in contact with the hypodermis for 12-36 hours after ecdysis. Afterwards the formation of inner endocuticle, in which pore canals are absent, cuts them off in the outer endocuticle, where they remain as strongly basic staining filaments (Text-fig. $3 d$ ).

Measurements of hand sections of living cuticle showed that $5^{-6}$ days after moulting the inner endocuticle reaches a total thickness of about $5 \circ \mu$, of which about $30 \mu$ is laid down in the first $2 \frac{1}{2}$ days. From $5 \frac{1}{2}$ days until formation of the prepupa at about 7 days, little or no increase in thickness of the cuticle occurs. In Carnoy-fixed preparations of the developing larval cuticle of Bombyx mori, Kuwana (1933) observed an increase in thickness at the beginning and end of the instar with an intervening relatively quiescent period. If such measurements on fixed material are correct the mode of growth of the Bombyx cuticle is somewhat different from that of Diataraxia.

\section{Formation of the Cuticulin Layer and Exocuticle}

The young $5^{\text {th }}$ instar epicuticle cannot be separated from the overlying

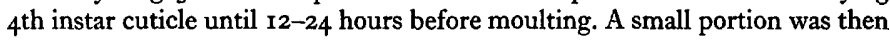
removed and placed in chlorinated nitric acid in the cold. The attached hypodermis and newly formed endocuticle rapidly dissolved, leaving a fine transparent membrane which on heating broke down with the liberation of oily droplets. Thus as in Rhodnius (Wigglesworth, 1947) the cuticulin layer is well defined at an early stage. At this stage of development the staining reactions of transverse sections of the new cuticle are of interest. After Bouin fixation the newly formed cuticulin layer stains with eosin but not with iron haematoxylin, and in this respect has the same properties as the outer epicuticle of Sarcophaga (Dennell, 1946), but about 6 hours prior to moulting, when 4-5 $\mu$ of endocuticle has been laid down, Bouin fixed, iron haematoxylin stained preparations begin to show deeply stained pore canal strands which appear to be discharging deeply staining material under the cuticulin layer to form the exocuticle. It should be noted that when this takes place, endocuticle formation has already begun, and thus the basic-staining material is laid down in the outer region of the endocuticle. This provides further evidence that the resulting layer contains chitin and is a true exocuticle. 
It will be remembered that if the mature larval cuticle is treated with cold concentrated nitric acid the exocuticle is only dissolved after several hours. Now when a portion of the cuticle containing newly formed exocuticle is placed in cold concentrated nitric acid all layers except the cuticulin layer are rapidly destroyed. Thus the exocuticle is not yet in the mature resistant state nor does it show increase in resistance until after ecdysis.

\section{Hardening of the Larval Exocuticle}

In the development of typical hard cuticle, hardening and increase in resistance of the exocuticle are caused by tanning of exocuticular protein by quinones (Pryor, I940 $a$ and $b$ ). This process occurs at the same stage of development as the increase in resistance of the Diataraxia larval exocuticle, and the general similarity suggested that dihydroxyphenols are responsible for tanning in the thin exocuticle of soft cuticle.

The secretion of dihydroxyphenols in the developing cuticle may be studied by means of the argentaffin reaction (Lison, 1936), though it should be made clear that this test is not specific. However, material in the Diataraxia cuticle which colours red or red-black with ammoniacal silver hydroxide has been called dihydroxyphenol. Additional evidence to show that this conclusion is justified will be given later.

The old $4^{\text {th }}$ instar cuticle of the moulting Diataraxia larva cannot be separated from the underlying $5^{\text {th }}$ instar cuticle until 12-24 hours before moulting. If a portion of $5^{\text {th }}$ instar cuticle is exposed at this stage and the larva immersed in 5 per cent. ammoniacal silver hydroxide for $\frac{1}{2}$ hour, washed, fixed in Carnoy, and the cuticle examined in surface view under the high power of the light microscope, it is seen that the new cuticle is only slightly stained. However, silver hydroxide has penetrated everywhere and heavily stained the underlying hypodermal cells. Prior treatment with cold chloroform for 5 minutes causes no significant difference in intensity or distribution of silver staining. Thus dihydroxyphenols are not present in the cuticle at this stage of development.

Some 6 hours before moulting the old cuticle can be separated at the muscle insertions and immersion in ammoniacal silver hydroxide as before again causes heavy staining in the hypodermis, showing that the cuticle is still permeable. The developing exocuticle stains light red, but at the muscle insertions it stains dark brick-red or black, indicating the presence of dihydroxyphenols. It was not possible to determine whether the cuticulin layer as distinct from the exocuticle caused reduction of ammoniacal silver hydroxide. However, after immersion in chloroform followed by treatment with ammoniacal silver hydroxide, many areas of the soft cuticle show brick-red staining droplets at the openings of the pore canals (Pl. II, fig. I4). This suggests that dihydroxyphenols are now being transported in the pore canals and that chloroform disrupts a layer which allows them to escape through the external openings of the pore canals. 
It is remarkable that at this stage of development (about 6 hours before ecdysis) the cuticle is highly permeable to ammoniacal silver hydroxide and yet chloroform treatment is required to expose dihydroxyphenols in the pore canals. Moreover, the following evidence suggests that the pore canals themselves provide the path for penetration of ammoniacal silver hydroxide solution to the hypodermis: (I) electron micrographs show that the outer epicuticle which is hydrofuge does not extend over the openings of the pore canals; (2) between the wall of the pore canal and the pore canal strand is a welldefined annular space which prior to moulting provides a direct path through the endocuticle to the hypodermis; (3) after immersion of a larva with exposed new cuticle in ammoniacal silver hydroxide without prior chloroform treatment, particles are sometimes precipitated in the lumen of the pore canals but not within the body of the endocuticle.

Thus, it would appear that the lumen of the pore canals is not responsible for transport of dihydroxyphenols and it can only be assumed that these are transported by the pore canal strands which are themselves surrounded by some form of waterproofing film. If the latter is destroyed by chloroform treatment the dihydroxyphenols are released at the openings of the pore canals when they will then reduce ammoniacal silver hydroxide.

At about $\frac{1}{2}$ to $\mathrm{I}$ hour prior to moulting, permeability of the cuticle to ammoniacal silver hydroxide becomes reduced. The hypodermis stains less strongly and in some areas not at all. The exocuticle is also unstained, though the muscle insertions through which fibrils still pass to the old cuticle stain heavily. Dotted over the dorsal surface of the epicuticle are circular areas sometimes $10-15 \mu$ in diameter which stain intensely, but if the cuticle is first immersed in chloroform there is no sign of their presence. The significance of these areas is not understood.

If a larva at ecdysis is immersed in ammoniacal silver hydroxide for $\frac{1}{2}$ hour there is complete absence of staining everywhere. Thus, the waterproofing layer in Diataraxia is laid down just prior to ecdysis, an observation in agreement with those of Wigglesworth on Rhodnius (1947) and Tenebrio (1948), where, except over small areas, waterproofing is completed immediately before ecdysis.

For $1-2$ days after ecdysis removal of the waterproofing layer with chloroform or by abrasion exposes the silver staining polyphenol droplets at the tips of the pore canals (PI. II, figs. 15, 16). In older larvae they may sometimes be observed in limited areas generally around the limb bases, but elsewhere treatment with cold or hot chloroform fails to expose them, though light staining of the exocuticle and sometimes of the underlying hypodermis shows that ammoniacal silver hydroxide has penetrated the cuticle.

Harsh abrasion of the mature cuticle damages the body of the epicuticle and allows penetration of ammoniacal silver hydroxide which readily stains the abraded areas. Under the low power of the microscope the stained areas appear similar to those obtained after abrasion of the newly emerged larva, but, if such cuticle is examined in transverse section, it is clear that staining is not 
due to droplets at the tips of the pore canals but is caused by ammoniacal silver hydroxide which has precipitated beneath the exocuticle.

To summarize: at about 6 hours before moulting, material probably containing dihydroxyphenol appears in the pore canals and continues to be secreted until I-2 days after moulting. It is not discharged on to the outer surface of the epicuticle to form a layer. Therefore, the polyphenol layer as found in hard-bodied insects (Wigglesworth, 1947, 1948) is absent, perhaps a necessary precaution because excess dihydroxyphenol might induce further tanning in a cuticle which must retain its flexibility. The dihydroxyphenol is presumably secreted through the fine-branched filaments of the pore canal strands into the exocuticle and is responsible for limited tanning of this layer which as a result shows increased resistance to concentrated acids and alkalis. At about $\mathrm{I} \frac{1}{2}$ days after moulting the hardening process ceases in the exocuticle. It is significant that at this stage the pore canals become cut off from the hypodermis and thus are unable to conduct and secrete further dihydroxyphenols.

\section{Formation of The Cement LAYER}

As mentioned before, the cement layer can be readily stripped from the mature cuticle on a layer of collodion, deposited on a slide, and stained with iron haematoxylin. To determine when it is formed, this process was carried out on portions of cuticle at various stages of development. Examination showed that the cement layer was absent in all preparations obtained from the new cuticle prior to moulting, though in some an irregular net-like structure was stripped from the inter-segmental regions. This was considered to be an artifact produced by drying out of the digested remains of the old cuticle. Such artifacts could be produced artificially, but they were readily distinguishable under the electron microscope and never formed a continuous well-defined layer.

Collodion stripping of the cuticle at moulting and afterwards showed that a well defined cement layer had been formed. Thus as in Rhodnius and Tenebrio (Wigglesworth, 1947, 1948) the cement layer is laid down shortly before or at ecdysis.

\section{Secretion of the Cement Layer}

Wigglesworth (1947, 1948) has shown that in Rhodnius and Tenebrio the time of formation of the cement layer coincides with discharge of the dermal glands which he suggests are responsible for the formation of this layer. These observations suggested a study of the dermal glands of Diataraxia.

In lepidopterous larvae the large segmentally arranged glands were first described by Verson ( 1890$)$. A pair in each segment lie laterally just above the limb bases in the thorax and in a similar position in the 8th abdominal segment. In the thoracic segments and in the Ist-8th abdominal segments a gland is situated dorso-laterally above and just anterior to each spiracle. Each gland consists of three modified hypodermal cells: the canal cell, the intercalary cell, and the large gland cell. 


\section{Development of Verson's Gland in the $4^{\text {th }}$-5th Instar of the Diataraxia larva}

In Diataraxia the large gland cells are either barrel-shaped (ventro-lateral thoracic glands) or flattened and somewhat heart-shaped (dorso-lateral glands; Pl. II, fig. 17). First, their development was studied in detail by examination of $10 \mu$ sections of moulting $4^{\text {th }}-5^{\text {th }}$ instar larvae which were stained in Mallory or iron haematoxylin and eosin. Bouin and Carnoy were used as fixatives. These preparations confirmed the observations of Schurfeld (I935) regarding the period of development and time of discharge of the glands. At cessation of feeding prior to beginning of the moulting period the glands show an illdefined basic staining central nucleus and an acidic staining cytoplasm containing numerous small vesicles (PI. II, fig. I8). During the next 24 hours the glands and the vesicles enlarge somewhat and the nucleus begins to show a well-defined branched structure. At the end of this period, about 24 hours before ecdysis, preparations show that each vesicle is surrounded by a welldefined membrane and contains one or more granules or droplets of material with basic staining properties similar to the nucleus (Pl. II, fig. I9; Pl. III, fig. 20). The granules, which were observed by early investigators but not mentioned in more recent publications, are sometimes relatively large and in the form of droplets in ventro-lateral thoracic glands but are smaller in the dorso-lateral glands (Pl. III, fig. 2I). Mallory-stained sections show that the droplets are not homogeneous but contain lightly stained particles (Pl. III, fig. 20). Noticeable development of the gland occurs in the 12 hours prior to ecdysis. The large gland cell increases in size and the cytoplasmic vesicles enlarge and apparently coalesce to some extent. The basic staining droplets apparently divide into smaller particles and finally break down completely, so that each vesicle becomes filled with a thinly dispersed material (Pl. III, fig. 22). Immediately prior to discharge the walls of the vesicles disintegrate and the nucleus is pushed to one side of the single lumen which is now filled with secretion. It would thus appear that solid material is actively secreted into the gland vesicles and that the secretion is not merely a watery fluid as suggested by Schürfeld (1935) and Kühn and Piepho (1938).

Further experiments were carried out to determine the nature of the large gland cell secretion. Individual glands were dissected in Ringer's solution from larvae at various stages of development. On treatment with I per cent. a-naphthol in 95 per cent. alcohol followed by concentrated sulphuric acid (Molisch's test), the response was negative. This suggested the absence of glucoproteins which as mucin might be expected to act as a lubricant facilitating the casting of the old cuticle. Response to the nadi reagent (Lison, I936) was also negative. This suggested the absence of the oxidase systems and of phenolic materials (Dennell, 1947). Prolonged treatment in the nadi reagent (10-20 minutes) showed pale staining granules in some glands. These were also observed in unfixed glands treated with 0.05 per cent. methylene blue in Ringer's solution. Clearly the basic staining granules observed in sectioned material are present in the living cell and are not an artifact of fixation as sug- 
gested by Verson (1911) and Schulze (I912). Plotnikow (1904) thought that they were chromatic droplets, and to test this suggestion a series of glands were slightly macerated on coverslips, fixed in saturated mercuric chloride -2 per cent. acetic acid, and then subjected to the Feulgen reaction (Lison, 1936). The granules, however, did not stain. It is of interest to record the distribution of nucleoprotein as shown by these preparations. In the actively secreting cell about 12 hours prior to ecdysis the nucleus ramifies throughout the cell and nucleoprotein in the form of well-defined minute particles is present over much of the wall of each vesicle. When secretion ceases and the vesicles break down, the nucleoprotein becomes aggregated and fibrous in appearance. Clearly the nucleus is actively concerned in secretion, but the material secreted into the vesicles does not contain desoxyribonucleic acid.

To test for protein the ninhydrin test was carried out by warming with ninhydrin in $5^{\circ}$ per cent. glycerol (Wigglesworth, 1942). With unfixed glands gentle warming produced an immediate positive response and small droplets in the gland vesicles showed strong purple staining. Prior fixation with Bouin or to per cent. formalin resulted in much reduced response to ninhydrin. The nucleus became coloured, but elsewhere only a diffuse and pale-blue coloration was obtained.

To test for lipoid, glands attached to coverslips as before were fixed in Baker's formaldehyde and stained in sudan black B (Pantin, 1948). Preparations showed that each vesicle contained a large staining droplet (Pl. III, fig. 23). The droplets are well defined by about 24 hours before ecdysis when they stain rather lightly, though the surrounding protoplasm stains strongly even after immersion in the dye for periods as short as 3 minutes. In later stages of development the droplets begin to stain more heavily, and as the vesicles enlarge they enlarge correspondingly and throughout development probably fill each vesicle, though in unfixed preparations they appear to have shrunk. Just before ecdysis when the vesicle walls break down, the droplets coalesce. Thus Verson's gland secretion contains a lipoid. Probably it is the presence of this lipoid which after fixation in formaldehyde masks the response of the protein to ninhydrin. Moreover, if a gland is fixed in formaldehyde and treated with iron haematoxylin the contents of the vesicles fail to stain (Pl. II, fig. 17) unless the lipoid is first removed with alcohol. Glands fixed in Baker's formaldehyde were transferred to absolute alcohol overnight and several were also fixed in Carnoy which would undoubtedly remove any lipoid present. They were then immersed in sudan black B and examined. The large sudanstaining droplets had disappeared and the gland vesicles were empty except for the granules or thinly dispersed material similar to those visible in the haematoxylin-stained sections.

Thus, it is concluded that lipoid as well as protein is secreted by Verson's gland. The relationship of the haematoxylin- and Mallory-staining protein granules to the sudan-staining droplets cannot be determined with certainty from fixed preparations. Mallory-stained paraffin sections of the ventral thoracic glands 24 hours before ecdysis show droplets which resemble the 
sudan-staining droplets, but at later stages of development these droplets or granules occupy but a small part of the vesicle, while the sudan-staining droplets probably fill it completely. Moreover, the lipoid can be removed from the vesicles with absolute alcohol, leaving the granules undissolved. This suggests that protein granules are present as distinct particles within each sudanstaining droplet. However, just before ecdysis the granules break down into a thinly dispersed material and thus it seems probable that the secretion at discharge consists of an emulsion containing protein which is now associated with the lipoid in the form of a lipoprotein.

It is interesting that glands fixed in 2 per cent. osmium tetroxide for 10 minutes turn but light brown in colour. If the gland is slightly macerated, refractile droplets, which are not miscible with Ringer or osmic solution, escape and become clearly defined after osmic treatment, but show little or no staining response (PI. III, fig. 24). No further staining occurs even after immersion in osmium tetroxide for 24 hours. Now it has been shown that many lipoprotein complexes in cells and body fluids fail to respond to various tests for lipoids, although it can be demonstrated that considerable quantities of saturated and unsaturated lipoids are present (Lovern, 1942). These complexes are dissociated and the lipoid removed by treatment with absolute alcohol. This information may explain the absence of response to stains of the type B dermal gland of Rhodnius (Wigglesworth, 1947, 1948). The glands contain a large distended oval vesicle whose contents colour pale violet with ninhydrin but do not stain with iron haematoxylin, osmium tetroxide, or other fat stains. There seems little doubt that these glands secrete a lipoprotein. Perhaps this is also true of dermal glands in the tick Ornithodorus, where the gland lumen becomes filled with a 'colourless secretion' (Lees, 1947).

\section{Discharge of Verson's Gland}

The moulting larva remains quiescent until about ro minutes before ecdysis, when muscular contractions begin throughout the body. These consist of dimpling movements of the cuticle and some waves of contraction. The muscle insertions on the old epicuticle are detached during this process, and the limbs and tracheal exuviae partly withdrawn. At the same time, as observed by Schürfeld (1935), a liquid is discharged into the space between the old and the new cuticle. To determine whether this liquid was discharged by Verson's glands a moulting larva of Diataraxia was fixed with Bouin, just as liquid secretion was beginning. Sections showed that several of the glands were in the act of discharging a thinly dispersed material which was visible in the exuvial space. A gradient in time of discharge was noticed-anterior glands having discharged their secretion whilst posteriorly the glands were still undischarged. In addition, the act of discharge was observed by removing the old cuticle from the abdomen of a moulting Diataraxia larva just as the process was taking place. Liquid was emerging exactly where the gland duct opened in a position dorsal and just anterior to the spiracles. The liquid, which appeared transparent, ran along the cuticle folds and in a few moments dried up. The 
larva was then immersed in 5 per cent. ammoniacal silver hydroxide for $\frac{1}{2}$ hour. The gland secretion was defined by faint red-silver staining.

\section{Relation of Verson's Gland Secretion to Formation of the Waterproofing Layer}

The old cuticle was removed from the abdomen of a moulting $4^{\text {th }}$ instar larva just as Verson's glands were about to discharge, and the exposed new cuticle was immersed in ammoniacal silver hydroxide for $\frac{1}{2}$ hour. Silver staining of the cuticle was limited to some of the muscle insertions and to a number of the previously mentioned areas, the significance of which is not understood. Thus, before Verson's glands have discharged, waterproofing is practically complete. This suggests that Verson's glands are not responsible for secretion of the waterproofing layer. Confirmation was obtained by removing the exuvial head capsule of a larva some hours prior to moulting when the new cuticle was still permeable to water and stained readily in ammoniacal silver hydroxide. Celloidin enamel was used to glue the cut edge of the body exuvium to the new cuticle just behind the head. This prevented passage of secretion from the exuvial space on to the larval head which itself contains no dermal glands. When Verson's gland had secreted and the larva was attempting to moult, the head was immersed in ammoniacal silver hydroxide for $\mathrm{I}$ hour. No staining occurred, thus showing that the waterproofing wax layer had been formed in the absence of Verson's gland secretion.

\section{Verson's Glands and the Formation of a Cement Layer}

In the moulting Diataraxia larva it has been shown that discharge of Verson's glands and formation of a cement layer both occur just before the end of ecdysis. Now these two processes must occur almost simultaneously. Cement layer formation over the muscle insertions cannot take place until the musclefibre attachments between the old and new cuticle have been broken. The latter process occurs about ro minutes prior to ecdysis and thus the cement layer must be formed during the following 10 minutes. During this period no observed secretory process takes place except the discharge of Verson's glands, and thus there seems little doubt that as in Rhodnius and Tenebrio (Wigglesworth, 1947, 1948) the dermal glands are responsible for secretion of the cement layer. The nature of the gland secretion suggests that the cement layer consists of a lipoprotein.

\section{Changes following Discharge of Verson's Gland}

Directly after secretion, the large gland cell collapses and preparations show a rather ill-defined nucleus and disorganized cytoplasm. However, in some glands, vesicle formation begins in the cytoplasm just after ecdysis, though little further change occurs until the beginning of the next moult.

Previous investigators have noticed that just after the large gland cell has discharged, the exit duct is blocked by a plug of material, well defined by its ability to stain intensely with haematoxylin. Schürfeld (1935) suggested that this consisted of swollen fragments of the lining of the gland duct which 
had been partially digested by a secretion from the intercalary and canal cells. However, in Diataraxia the duct lining of the canal cell appears to remain intact and may be observed surrounding the plug. The lining of the duct in the intercalary cell is extremely thin and generally ill defined and it is difficult to conceive how in Diataraxia a relatively large plug is formed by digested fragments of such a duct wall.

The following observations provide information on the structure and formation of the plug. The plug is dark brown in colour. This indicates the presence of phenolic materials and suggests that it consists of tanned protein. Now the intercalary cell stains strongly with ammoniacal silver hydroxide and moreover gives a positive nadi response in the presence of cyanide (Dennell, 1947). This suggests that the intercalary cell secretes a dihydroxyphenol which would form the necessary quinone for the tanning process. The source of protein is not known. Perhaps in addition, the intercalary cell discharges dihydroxyphenol into the large gland cell secretion as it passes through the gland duct. This would account for the ability of the discharged secretion and of the cement layer to stain with ammoniacal silver hydroxide and would suggest that the cement layer consists of a lightly tanned lipoprotein.

\section{Comparison of Hard and Soft Cuticle}

It has been shown already that limited hardening occurs in the exocuticle of soft cuticle and that the material responsible is probably a dihydroxyphenol transported from the hypodermis by means of the pore canals. However, certain small areas of the Diataraxia cuticle consist of typical hard cuticle with a well-defined exocuticle and pore canal system essentially similar to that of hard-bodied insects (Wigglesworth, 1933, 1948; Richards and Anderson, 1942). In these insects the pore canals are connected to the hypodermis throughout the life of the insect, a condition which appears to be fundamentally different from that of soft cuticle.

\section{Properties of Hardened Cuticle of Diataraxia}

In the hardened areas the cuticulin layer is over $0.5 \mu$ thick, compared with about $0.2 \mu$ for soft cuticle, and it has a flat as distinct from tuberculate surface. $2 \mu$ Mallory-stained transverse sections of the mature hardened cuticle show the pore canals as fine red-staining strands passing from the hypodermis through the inner endocuticle, branching on the exocuticle, and then penetrating the cuticulin layer (Pl. III, fig. 25). Both the pore canals and the strands they contain are finer and less readily distinguishable than those of soft cuticle. However, penetration of the pore canals through the cuticulin layer to the surface or to an unmeasurable distance beneath it is very distinct, thus agreeing with the observations of Wigglesworth (1948), but differing from those of Richards and Anderson (1942) who state that in Periplaneta the pore canals end blindly in the endocuticle.

The exocuticle generally stains strongly with iron haematoxylin, though in the hardest areas the staining ability is lost. It also stains in ammoniacal silver 
hydroxide, suggesting that phenolic materials are present and that the method of hardening is the same as in typical hard-bodied insects, namely, the tanning of cuticular protein by quinones (Pryor, 1940 $a$ and $b$ ). If the complete larval cuticle of Diataraxia is cleaned from body tissues and examined in surface view and transverse section after immersion overnight in ammoniacal silver hydroxide, the exocuticle of soft cuticle is stained, though not strongly, but the hardened areas form well-defined black or brick-red staining patches of exocuticle, the staining being heaviest in the mouth parts, proleg crotchets, head, and fore limbs, weaker in prothoracic and last abdominal tergal shields, and weakest in small shield-shaped pads on the outer surface of the prolegs. This ability to reduce ammoniacal silver hydroxide is related to degree of hardness and, moreover, the natural colour varies from light amber in the hardest to colourless in the least hardened areas.

Table VI shows the properties of these areas compared with those of $(x)$ hardened cuticle at moulting, and (2) typical soft cuticle.

TABle VI. Properties of Hard and Soft Cuticle of the Diataraxia Larva

\begin{tabular}{|c|c|c|c|c|}
\hline & \multicolumn{3}{|c|}{ Hard areas of cuticle } & \multirow{3}{*}{$\begin{array}{c}\text { Soft cuticle } \\
\text { Mature } \\
\text { exocuticle }\end{array}$} \\
\hline & \multicolumn{2}{|c|}{ Mature exocuticle } & \multirow[b]{2}{*}{$\begin{array}{l}\text { Exocuticle at } \\
\text { moulting }\end{array}$} & \\
\hline & Hardest areas & $\begin{array}{c}\text { Least hardened } \\
\text { areas }\end{array}$ & & \\
\hline $\begin{array}{l}\text { Natural colour } \\
\text { Response to am- } \\
\text { moniacal silver } \\
\text { hydroxide }\end{array}$ & $\begin{array}{l}\text { Light amber } \\
\text { Stains black or } \\
\text { brick-red }\end{array}$ & $\begin{array}{l}\text { Colourless } \\
\text { Stains brick- } \\
\text { red }\end{array}$ & $\begin{array}{l}\text { Colourless } \\
\text { Stains brick- } \\
\text { red }\end{array}$ & $\begin{array}{l}\text { Colourless } \\
\text { Stains light } \\
\text { red }\end{array}$ \\
\hline $\begin{array}{l}\text { Response to iron } \\
\text { haematoxylin }\end{array}$ & $\begin{array}{l}\text { Staining vari- } \\
\text { able, some- } \\
\text { times slight } \\
\text { or not at all }\end{array}$ & Stains heavily & Stains heavily & Stains heavily \\
\hline
\end{tabular}

It is clear that the above series represent intermediate stages in the development of typical hard cuticle (cf. Pryor, $1940 b$ ). On this basis it would appear that typical phenolic tanning occurs in the soft cuticle as well as in the hard cuticle of the Diataraxia larva, the only notable difference being the extent of tanning, which in the former occurs to a limited extent in an exocuticle $0.5 \mu$ thick, but in the latter occurs extensively in an exocuticle which may be over $I I \mu$ thick.

\section{Secretion of Dihydroxyphenol and Protein}

Kühn and Piepho (1938) showed that in partial pupation spots of Ephestia strongly basic-staining material is secreted through the developing epicuticle and may form droplets in the cavity between the old and the new cuticle. Partial pupation was similarly induced in the pupating Diataraxia latva. The droplets not only stained with haematoxylin but gave a positive ninhydrin response after fixation in ro per cent. formaldehyde and also stained red in ammoniacal silver hydroxide. This suggests that they contain protein and 
dihydroxyphenol. The discharge of this material occurs at the same period as the discharge of the material containing dihydroxyphenol observed by Wigglesworth in Rhodnius (1947) and Tenebrio (1948), and there seems little doubt that the two secretions are homologous. Wigglesworth (1947, 1948) showed that the pore canals were responsible for secretion of 'material' containing dihydroxyphenol, and thus the present findings provide evidence to substantiatse his

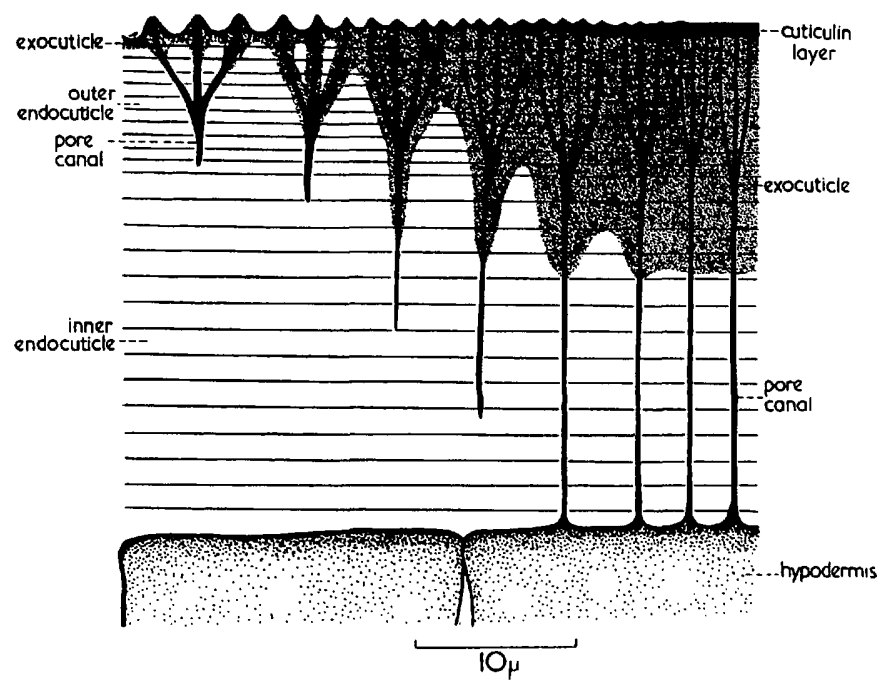

TExT-FIG. 4. Transverse section through the edge of a proleg pad showing transformation from soft to hard cuticle. Transformation occurs gradually over a length of about $200 \mu$, but in this diagram the various stages have been compressed into about $40 \mu$.

suggestion that the material consists of protein and that both protein and dihydroxyphenol are secreted by the pore canals. Moreover, a study of the slightly hardened areas of the Diataraxia cuticle provides additional evidence. Transverse sections of a proleg pad show gradation of structure from the condition typical of soft cuticle on the outside to that of hard cuticle towards the centre of the pad. The gradation is characterized by an increase in thickness of the cuticulin layer, flattening of the tubercles and extensive development of the exocuticle (Text-fig. 4). At the edge of each pad the pore canals are typical of soft cuticle (Pl. I, fig. 8) and are confined to the outer endocuticle, but towards the centre they extend deeper into the inner endocuticle until finally they connect with the hypodermis. The distribution of basic-staining exocuticular protein in relation to the pore canals is important. Transverse sections show that at the edge of the pad of hardened cuticle each pore canal is 
surrounded by a narrow basic-stained area of exocuticle. Increase of the staining area round each pore canal (P1. III, fig. 26), followed by coalescence to form a thick exocuticle, coincides with the extension of the pore canals into the inner endocuticle (Text-fig. 4). Thus, the longer the period during which the pore canals are in contact with the hypodermis the greater is the extent of secretion of exocuticular protein. This provides conclusive evidence that the protein is transported by the pore canals.

Preparations of developing cuticle of the Diataraxia larva show that discharge of protein and dihydroxyphenol by the pore.canals begins about 6 hours before ecdysis. In soft cuticle these materials form a thin exocuticle, the process being complete by about $\mathrm{I}-2$ days after ecdysis. In the hard areas of cuticle the process of exocuticle formation is much more extensive. Secretion of exocuticle material begins in the outermost layers of the endocuticle and then extends inwards. Protein deposition keeps ahead of tanning as shown by the fact that in the Diataraxia cuticle the inner limit of the exocuticle as defined by its ability to stain with iron haematoxylin is greater than the limit of the area which reduces ammoniacal silver hydroxide. In the Diataraxia cuticle the process of hardening in such areas as the head, although occurring mainly during the first day after moulting, continues to a limited degree during the later development of the instar. Thus, $\mathbf{x}-\mathbf{2}$ days after moulting the thickness of the exocuticle (the silver-reducing area) in the head capsule is about $7 \mu$. On the fifth day it has generally increased to about $\mathrm{I} \mu$ and in some areas an inner and less heavily stained area of exocuticle about $8 \mu$ thick has also been formed. This suggests that hardening materials continue to be transported from the hypodermis to the exocuticle for some time after ecdysis, and helps to explain why the pore canals of hard cuticle maintain continuous contact with the hypodermis.

\section{Functions of the Pore Canals}

The functions of the pore canals have been discussed previously by a number of authors and it is generally agreed that they act as a conducting system between the hypodermis and the outer layers of the cuticle. Wigglesworth $\left(1947,194^{8}\right)$ has shown that the pore canals are responsible for conduction and secretion of dihydroxyphenols in the developing cuticle of Rhodnius and Tenebrio, though it is of interest that in Sarcophaga, where hardening occurs in the mature larval cuticle, dihydroxyphenols are transported in the absence of pore canals (Dennell, 1947). There is no evidence to support suggestions that the pore canals are responsible for transport of enzymes, proteins, and waxes, while Dennell (1946) has shown that secretion of endocuticular material by the pore canals is unlikely.

The present findings, based on the studies of the developing soft and hard cuticle of the Diataraxia larva, have given some information on the functions of the pore canals. The conclusions may be summarized as follows: in the cuticle two forms of conducting pore canal system may be distinguished. The first in soft cuticle functions only during the early stages of development and 
the second in hard cuticle is functional for a much longer period, probably throughout the life of the instar. In soft cuticle the pore canal strands transport basic-staining protein to form the exocuticle and also dihydroxyphenols which presumably are oxidized to quinones and cause limited tanning of the exocuticular protein. With regard to Diataraxia it is of interest that when the limited tanning of the exocuticle has been completed the hardening process is extended to the pore canal strands in which the residual protein and phenol apparently react as in the exocuticle. The pore canals then become cut off from the hypodermis by the developing inner endocuticle.

In hard cuticle protein and dihydroxyphenol secretion by the pore canals is more extensive and the degree of tanning of the exocuticle more nearly complete. This process, which continues for a much longer period than in soft cuticle (perhaps throughout the life of the insect or instar), requires the maintenance of a conducting pore canal system from the hypodermis.

\section{Discharge of the Moulting Fluid}

The hypodermal cells are responsible for secretion and afterwards for reabsorption of the moulting fluid (Wigglesworth, 1933). During both these processes the moulting fluid has to pass through the developing new cuticle. Now, in the moulting Diataraxia larva it has been shown already that prior to ecdysis the pore canal lumen provides a direct path for conduction of watersoluble materials, such as ammoniacal silver hydroxide, through the cuticle from the exuvial space to the hypodermis. In particular the external openings of the pore canals would appear to provide the only path whereby watersoluble materials can pass through the hydrofuge cuticulin layer. Thus it is suggested that the pore canal lumen is responsible for transport of the moulting fluid.

\section{Transport of Waterproofing Waxes through the Cuticle}

If pore canals are required for the transport of waterproofing waxes, the soft cuticle of Diataraxia larva should be incapable of recovery of waterproofing after abrasion because the $5^{\circ} \mu$ thick inner endocuticle is devoid of pore canals. Therefore it is of interest to study the phenomenon of recovery of waterproofing in this insect.

With Diataraxia it was found that serious errors were involved in studying water loss over a period of days with the same individual. In the first place the larva is an active feeding stage, and determination of weight loss over a period of hours is complicated by the ejection of faeces. This was prevented by starving the larva, blocking the anus, and inactivating it by ligaturing the head. However, the rate of water loss of such an abraded larva in dry air, exposed only for short periods, caused such depletion of body water that recordings of water loss on subsequent days showed an abnormally low figure. Thus a batch of five larvae of average weight of $0 \cdot 28 \mathrm{gm}$. showed a water loss of $19 \cdot 4 \mathrm{mg}$. per larva per hour during a 3 -hour exposure to dry air directly after abrasion. They were kept at roo per cent. relative humidity until 
the next day, when they showed a water loss of $10.3 \mathrm{mg}$. per larva. On the third day the larvae had shrivelled: two were dead and the rate of loss was $3.2 \mathrm{mg}$. per larva. A separate batch similarly abraded and then kept continuously at 100 per cent. relative humidity showed a water loss of $19.2 \mathrm{mg}$. per larva per hour in dry air 4 days after abrasion. Thus, the apparent recovery of waterproofing in the first batch was caused entirely by depletion of body water. It should be noted that a decapitated larva seems incapable of recovery of waterproofing.

The following procedure was adopted. Batches of larvae were abraded by rubbing the dorsal surface of the first six abdominal segments with a piece of paper dipped in Almicide dust. As far as possible the procedure was standardized and an attempt was made to abrade a similar area of each larva. Adhering dust was washed from each larva and five larvae immediately removed, ligatured round the neck and killed in ammonia vapour. The ligature was carried out to prevent regurgitation which might contaminate the cuticle. Sources of water loss were then carefully occluded. Efficient occlusion of the mouth was not easy, and accordingly the head was removed and the cut end of the neck, the anus, and the spiracles covered with a spot of celloidin solution. The larvae were hung in a small desiccator over phosphorus pentoxide at $25^{\circ} \mathrm{C}$. for I hour. They were then weighed, replaced in the desiccator and reweighed after a further $\mathbf{z}$ hours to determine water loss during this period, after which they were discarded. The remaining abraded larvae were placed in dishes with food and kept at $25^{\circ} \mathrm{C}$. and 100 per cent. relative humidity. On the following day a further five larvae were removed and treated as above, this process being continued at daily intervals until the larvae were 8 days old.

Three batches of about forty larvae were abraded and a fourth control batch, apart from being unabraded, was treated in the same way as the others in every respect. Of the abraded larvae one batch consisted of 5 th instar larvae abraded within about 12 hours after moulting. It will be remembered that in the cuticle of larvae of this age, functional pore canals still connect the hypodermis to the epicuticle. Abrasion of this batch was carried out by exerting slight pressure on the filter-paper, a process which removes the waterproofing layer and generally exposes silver-staining droplets at the tips of pore canals. Text-fig. $5 a$ shows that water loss expressed as mg. per larva per hour increased somewhat during the 2 days following abrasion-it then decreased until it reached a figure which remained approximately constant at a level somewhat higher than that of the control.

The other two batches of treated larvae were abraded at about $\mathbf{2}$ days after moulting when the pore canal contents had become chitinized and sclerotized and a $10-20 \mu$ thick inner endocuticle without pore canals had been formed. At this stage silver-staining areas are seldom exposed when larvae are abraded gently. Rather more harsh abrasion, besides removing the waterproofing layer, knocks off the tips of the tubercles and allows ammoniacal silver hydroxide to penetrate the epicuticle and precipitate beneath it. One batch of larvae was abraded in this way whilst the other was abraded gently, as was the 
first batch. Text-fig. 5 a shows that rates of transpiration directly after abrasion were approximately the same in both treatments. On succeeding days it decreased steadily in the gently abraded batch, but the harshly abraded larvae showed an initial increase, though after $2-3$ days there was a rapid decrease.

The above results were confirmed in a second experiment. Four batches of

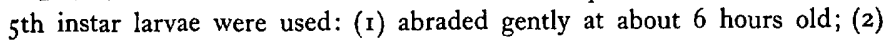
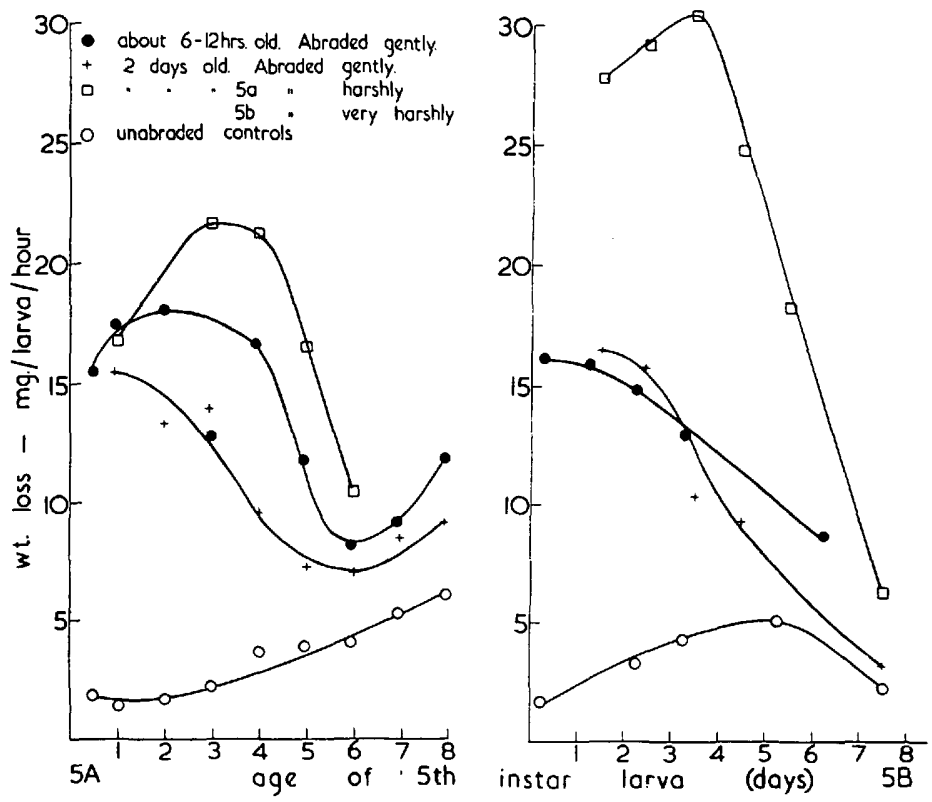

TExT-FIG. 5. Graphs showing recovery of waterproofing after the abrasion of the $5^{\text {th }}$ instar cuticle of Diataraxia. Batches of larvae were abraded and transpiration in dry air at $25^{\circ} \mathrm{C}$. was determined at intervals during the following seven days. Explanation in text.

abraded gently at about 2 days old; (3) abraded severely and extensively at about 2 days old; (4) unabraded controls. Text-fig. $5^{b}$ shows the results. The first two treatments showed a gradual decrease in water loss, the second reaching a final level very similar to the control. The third treatment showed an initial increase and then a very rapid decrease.

There was a slight difference of procedure in this experiment. Prior to determination of water loss, the larvae were not killed with ammonia but were ligatured round the neck, the head removed, and only the neck and anus blocked with celloidin. The fact that they were alive may account for the 
difference in water loss between living and dead larvae after about $5 \frac{1}{2}$ days (cf. Text-fig. $5, a$ and $b$ ). At this stage larval contraction begins prior to prepupal formation. In the living larva contraction by decreasing surface area might cause a reduction of transpiration, whereas the dead individual would be relaxed, and decrease in transpiration at prepupal formation would not be apparent.

The data demonstrate that larvae are capable of recovery of waterproofing after abrasion and, moreover, they show that there is no significant difference between rates of recovery of larvae abraded when the pore canals connect with the hypodermis, and of those abraded when the pore canals have become cut off by the inner endocuticle and their contents sclerotized. This suggests that the pore canals are not responsible for secretion of waterproofing waxes.

The final levels of transpiration reached by abraded larvae-somewhat higher than that of the controls-show that waterproofing is generally not completely restored, a fact previously demonstrated by Wigglesworth (1945) and Lees (1947). However, in one gently abraded batch the difference, if significant, was slight.

The process of recovery of waterproofing requires consideration. Electron micrographs show that the tips of the tubercles may be removed by harsh abrasion. The initial rise of transpiration in harshly abraded larvae would seem to occur when such damage to the framework of the epicuticle is being repaired. Only after this process has been completed can the superficial waterproofing wax layer be laid down. In some larvae the regenerated wax was observed as a white bloom easily rubbed off the cuticle, which melted into oily droplets when warmed (cf. Wigglesworth, r945).

Thus, during recovery after abrasion, and possibly also during formation of the waterproofing layer prior to ecdysis, waterproofing waxes can pass outwards through the substance of the endocuticle. It is possible that the waxes are discharged on to the epicuticle surface through the external openings of the pore canals, but as the epicuticle is readily permeable to lipoid materials (Wigglesworth 1945) there seems no doubt that waxes can pass more readily through the framework of this layer than through the pore canals which apparently have hydrophil properties.

\section{ACKNOWLEDGEMENTS}

The greater part of the above work was carried out during a year's secondment from Rothamsted Experimental Station to the Entomology Department of the Zoology School, Cambridge. I am most grateful to Dr. V. B. Wigglesworth and Dr. W. H. Thorp for making this possible, and I should like to thank Dr. F. Tattersfield for arranging the secondment. I am greatly indebted to Dr. Wigglesworth for his advice and criticism of the work and also wish to acknowledge the help and encouragement given by Dr. J. W. L. Beament.

The electron micrographs were taken at the Cavendish Laboratory and at Rothamsted Experimental Station, and I am much indebted to Dr. V. E. Cosslett and Mr. H. L. Nixon for providing every possible facility and also for their stimulating interest in the work. 


\section{REFERENCES}

Beament, J. W. L., 1945. J. exp. Biol., 2I, 115.

Bergmann, W., I938. Ann. Ent. Soc. Amer., 31, 315.

Campbell, F. L., 1929. Ibid., 22, 401.

DenNiell, R., r946. Proc. Roy. Soc. B, 133, 348.

- 1947. Ibid., 134, 79.

Fraenkel, G., and Rudall, K. M., 1947. Ibid., 11 1.

KUnn, A., and Piepho, H., 1938. Biol. Zbl., 58, 12.

Kuwana, Z., x933. Proc. Imp. Acad. Tokyo, 9, 280.

LEES, A. D., 1947. J. exp. Biol., 23, 379.

Lison, L., 1936. Histochimie Animale. Paris (Gauthier-Villars).

LOVERN, J. A., 1942. D.S.I.R. Food Investigation special report, no. 52.

MUthlethaler, K., 1949. Biochim. et Biophys. Acta, 3, 15.

Pantin, C. F. A., 1948. Notes on Microscopical Technique for Zoologists. Cambridge University Press.

Plotnikow, W., 1904. Z. wiss. Zool., 76, 333.

Preston, R. D., and Astbury, W. T., 1937. Proc. Roy. Soc. B, 122, 76.

PRYOR, M. G. M., 1940a. Ibjd., 128, 378 .

- I940b. Ibid., 393.

Ramsay, J. A., I935. J. exp. Biol., 12, 373.

REED, R., and Rudall, K. M., I948. Biochim. et Biophys. Acta, 2, 7.

Richards, A. G., and Anderson, T. F., I942. J. Morph., 71, 135.

- and KordA, F. H., 1948. Biol. Bull., 94, 212.

Schulze, P., 1912. Zool. Anz., 39, 433.

SchUrfeld, W., 1935. Arch. Ent. Mech., 133, 728.

Stemdman, H. F., 1947. Quart. J. micr. Sci., 88, 123.

Tupper-Carey, R. M., and Priestley, J. H., 1924. Proc. Roy. Soc. B, 95, 109.

Verson, E., 1890 . Zool. Anz., 30, 118.

- I9II. Z. wiss. Zool, 97, 457.

Webi, J. E., 1947. Parasitology, 38, 70.

Wigclesworth, V. B., x933. Quart J. micr. Sci., 76, 269.

I 942 . Bull. Ent. Res., 33, 205.

- 1945. J. exp. Biol., 21, 97.

- 1947. Proc. Roy. Soc. B, 134, 163.

- 1948. Quart. J. micr. Sci., 89, 197.

Yonge, C. M., 1932. Proc. Roy. Soc. B, 11 I, 298.

\section{EXPLANATION OF PLATES}

\section{Plate I}

Fig. 1. Electron micrograph of a $2 \mu$ thick transverse section of the dorsal cuticle showing outlines of the epicuticular tubercles. Note irregular shaped swellings at the tips of the tubercles. R.C.A. microscope. $50 \mathrm{kv}$. Magnification $\times 9,000$.

Fig. 2. Electron micrograph of the surface of the cuticulin layer obtained by treatment of new cuticle just prior to ecdysis with cold concentrated hydrochloric acid overnight. The tubercle has collapsed on one side owing to removal of the supporting exocuticle. Nickel shadowed. R.C.A. microscope. $50 \mathrm{kv}$. Magnification $\times 23,600$.

Fig. 3. Photograph of the cement layer in surface view showing the layer where it overlies part of two muscle insertions. Stripped with collodion. Overstained with iron haematoxylin. Magnification $\times 450$.

Fig. 4. Electron micrograph of the cement layer in surface view Siemen's microscope. $50 \mathrm{kv}$. Magnification $\times 5,200$.

Fig. 5. Electron micrograph of the cement layer at the edge of a muscle insertion. The tubercles are completely covered by the layer. Note plugs of material removed from the openings of the pore canals. The fine granular particles are probably impurities from the collodion used in the stripping process. Siemen's microscope. $50 \mathrm{kv}$. Magnification $\times 10,700$. 


\section{Way-Larval Cuticle of Diataraxia oleracea}

Fig. 6. Electron micrograph of the cement layer overlying the dorsal epicuticle of the exuvium. To differentiate the cement layer, the exocuticle was partly removed with concentrated hydrochloric acid. Presumably the exocuticle is still present in the tubercles which appear opaque. Siemen's microscope. $100 \mathrm{kv}$. Magnification $\times 5,300$.

Fig. 7. Electron micrograph of the lateral epicuticle in surface view. The exuvium was treated overnight with 5 per cent. pepsin $\left(\mathrm{pH} 2,32^{\circ} \mathrm{C}\right.$.), which removes the plugs blocking the openings of the pore canals at the tips of the tubercles. R.C.A. microscope. $50 \mathrm{kv}$. Magnification $\times 15,600$.

Fig. 8. Photograph of a transverse section of the mature lateral cuticle. In the outer endocuticle the tree-like pore canal strands stain strongly. One strand enters each epicuticular tubercle. Stained with iron haematoxylin. Magnification $\times 825$.

Fig. 9. Electron micrograph of lateral epicuticle in surface view. The cuticle was treated with concentrated hydrochloric acid for 10 minutes to remove, the endocuticle. The pore canal strands are unaffected by this treatment and remain attached to the undersurface of the epicuticular tubercles. Siemen's microscope. $100 \mathrm{kv}$. Magnification $\times 9,200$.

Fig. 10. Electron micrograph of an epicuticular tubercle in surface view. Stained with Altmann to define the fine filaments which connect each pore canal strand to the epicuticle or exocuticle. Siemen's microscope. $100 \mathrm{kv}$. Magnification $\times 10,200$.

Fig. I I. Photograph of a surface section of the outer endocuticle from the ventral integument between the prolegs. Fixed with Flemming and stained with iron haematoxylin to show the pore canals and pore canal strands in transverse section. Magnification $\times 825$.

Fig. 12. Electron micrograph of part of a lamella from the outer endocuticle treated 48 hours with 2 per cent. pepsin ( $\mathrm{pH} 2,32^{\circ} \mathrm{C}$.) and examined in surface view. Pore canals and indications of chitin fibres are visible. R.C.A. microscope. $60 \mathrm{kv}$. Magnification $\times 12,600$.

\section{Plate II}

Fig. 13. Electron micrograph of part of the same lamella as Pl. I, fig. 12, treated overnight with 5 per cent. potassium hydroxide at $60^{\circ} \mathrm{C}$. and examined in surface view. Chitin fibres and bundles of fibres are well defined. Nickel shadowed. R.C.A. microscope. $50 \mathrm{kv}$. Magnification $\times 37,100$.

Fig. 14. Photograph of the surface of the new epicuticle about 6 hours prior to ecdysis after immersion in cold chloroform for 5 minutes followed by 5 per cent. ammoniacal silver hydroxide for half an hour. The photograph is taken at a slightly oblique angle. 'Polyphenol' droplets may be seen on the tips of the tubercles at the openings of the pore canals. The cement layer is absent. Magnification $\times 825$.

Fig. 15. Photograph of the surface of the epicuticle about 24 hours after ecdysis after treatment as described for fig. 14. 'Polyphenol' droplets are exposed at the openings of the pore canals and the cement layer shows faint silver staining. Magnification $\times 45^{\circ}$.

Fig. 16. Photograph of the surface of the epicuticle about 24 hours after ecdysis, after abrasion with Almicide dust and immersion in 5 per cent. ammoniacal silver hydroxide for half an hour. In the abraded regions 'polyphenol' droplets are exposed at the tips of the pore canals. Magnification $\times 450$.

Fig. 17. Photograph of a whole mount of a mature Verson's gland from the abdomen of a moulting $4^{\text {th }}-5^{\text {th }}$ instar larva. The canal cell is absent. The diffusely branched nucleus of the large gland cell is well defined. Fixed in Baker's formaldehyde and stained with iron haematoxylin and light green. Magnification $\times 5^{\circ}$.

Fig. 18. Photograph of 10 $\mu$ section of the large gland cell of Verson's gland from a moulting $4^{\text {th }}$-5th instar larva about 2 days before ecdysis. Fixed in Bouin and stained with iron haematoxylin and eosin. Numerous small vesicles are present in the cytoplasm, but the nucleus is not well defined. Magnification $\times 225$.

Fig. 19. Photograph of a $10 \mu$ section of a 2nd ventral thoracic Verson's gland about 24 hours before ecdysis, treated as described for fig. 18 . The basic staining contents of the vesicles and the branched nucleus of the large gland cell are well defined. The intercalary cell is also present. Magnification $\times 225$.

\section{Plate III}

Fig. 20. Photograph of a ro $\mu$ section of a large gland cell from the 3 rd ventral thoracic segment at about the same stage as P1. II, fig. 19. Fixed in Carnoy and stained with Mallory. Each 
vesicle is surrounded by a membrane and contains an unevenly stained droplet. Branches of the nucleus ramify amongst the vesicles. Magnification $\times 975$.

Fig. 2x. Photograph of a $10 \mu$ section of a large gland cell from the 4 th abdominal segment at a rather later stage than PI. II, figs. I9 and 20 ; treated as described for Pl. II. fig, I8. Each vesicle contains a number of small droplets or granules. Magnification $\times 225$.

Fig. 22. Photograph of a $10 \mu$ section of a large gland cell from the 3 rd abdominal segment just prior to breakdown of the vesicle walls. Treated as described for P1. II, fig. 18. The vesicle contents consist of a thinly dispersed material. Magnification $\times 225$.

Fig. 23. Photograph of contents of a macerated abdominal gland at about the same stage of development as fig. 21. Fixed in Baker'B formaldehyde and atained with sudan black B to demonstrate lipoid. Both vesicle contents and the surrounding protoplasm stain readily. Magnification $\times 450$.

Fig. 24. Photograph of contents of a macerated abdominal gland from a larva at about the same stage of development as fig. 21 . Fixed in 2 per cent. osmium tetroxide. Vesicles in the body of the gland are visible and from some of them the contents have escaped in the form of unstained refractile droplets. Magnification $\times 45^{\circ}$.

Fig. 25. Photograph of a $2 \mu$ transverse section through the hard cuticle of a thoracic leg of the 5 th instar larva. The pore canals may be seen passing through both the endocuticle and the epicuticle and apparently opening on the surface. Fixed in Carnoy and stained with Mallory. Magnification $\times 825$.

Fig. 26. Photograph of a $6 \mu$ transverse section through the cuticle at the edge of a proleg pad. The pore canals are beginning to extend into the inner endocuticle and each is surrounded by a basic staining area of outer endocuticle.. Fixed in Bouin and stained with iron haematoxylin. Magnification $\times 825$. 